\title{
Empresas não Financeiras e o Impacto da Estratégia Maximizing Shareholder Value sobre o Emprego no Brasil
}

\section{Non-financial Firms and the Maximizing Shareholder Value Strategy Impacts over Employment in Brazil}

\author{
Luccas Assis Attílio* \\ Anderson Cavalcante***
}

Resumo: Esse artigo avalia a estratégia de maximizing shareholder value para uma amostra de empresas não financeiras de capital aberto entre 1997 e 2013 e estima seu impacto sobre o emprego em respectivos setores de atividade econômica. Para se estimar tais efeitos, utiliza-se o método de mínimos quadrados em dois estágios, com base na teoria da reação em cadeia. Os resultados indicam que o aumento da distribuição de dividendos, via maximizing shareholder value,tem efeitos negativos sobre o investimento produtivo, que, por sua vez, desacelera a criação de empregos.

Palavras-chave: Financeirização. Maximizing shareholder value. Empresas não financeiras. Emprego.

\begin{abstract}
This article investigates the maximizing shareholder value (MSV) strategy for a sample of non-financial publicly held companies between 1997 and 2013. It estimates the MSV impact over employment on the firms' respective sectors of activity. In order to estimate such effects the Two-Stage Least Squares method was used, with support of the Chain Reaction Theory. Results indicate that increases in shared dividends, via maximizing shareholder value strategy, have negative effects over the productive investment that, by its turn, slows down employment creation.
\end{abstract}

Keywords: Financialization. Maximizing shareholder value. Non-financial companies. Employment.

JEL Classification: G00; G30; E02; J60.

\section{Introdução}

Os anos após a Segunda Guerra Mundial podem ser divididos em três períodos em termos de regimes econômico internacionais. Sob a égide dos Acordos de Bretton Woods,presenciou-se um robusto crescimento do produto e emprego em diversas economias (ARRIGHI, 1994), além da expansão do comércio internacional.O setor financeiro atuava às vistas dos controles sobre câmbio e movimentos de capitais internacionais, o que limitava sua expansão, mas permitia

* $\quad$ Doutorando em Teoria econômica pela FEA/USP. Mestre em Economia pela Universidade Federal de Minas Gerais (UFMG). Professor do curso de Economia da Universidade Federal de Ouro Preto (UFOP). E-mail: luccas.attilio@ufop.edu.br

** $\quad$ Doutor pela University of Cambridge. Professor do curso de Economia da Universidade Federal de Minas Gerais (UFMG). E-mail: atmc@cedeplar.ufmg.br 
a flexibilidade da política econômica necessária para o crescimento e ao pleno emprego (MYRDAL, 1977).

Esse quadro se modificou ao final dos anos 1960 e início dos anos 1970, quando os Estados Unidos abandonam os Acordos de Bretton Woods, inaugurando o regime de interdependência. Com o esgotamento das tentativas de cooperação internacional, os choques de preços do petróleo e,por fim, o aumento da taxa de juros norte-americana em 1979,o quadro econômico internacional muito se agravou no período, com retração do produto e processo inflacionário em ascensão. As reformas adotadas a partir do fim dos anos 1970 caracterizaram-se pelo objetivo de liberalizar diferentes mercados nas economias domésticas (OSTRY;LOUNGANI;FURCERI, 2016). Entre essas medidas, destacou-se a liberalização financeira, um conjunto de políticas que defendia a abertura e a desregulamentação dos mercados financeiros nacionais.Com o fim da União das Repúblicas Socialistas Soviéticas (URSS), observa-se a instauração do atual regime de globalização (financeira), fruto da maior integração dos mercados mundiais, do aumento dos fluxos de pessoas, produtos, informação e, mais proeminentemente, dos fluxos de capitais e das operações financeiras (MISHKIN, 2009). A crescente onda de financeirização afeta diversos setores de atividades, inclusive influenciando as estratégias de acumulação de diferentes agentes econômicos. Entre as estratégias adotadas, inclui-se o maximizing shareholder value (MSV), ${ }^{1}$ ou "estratégia de maximizar o valor do acionista”, pela qual empresas priorizam a elevação do valor de suas ações e o pagamento de dividendos para os acionistas. Crescentemente, as empresas têm direcionado seus esforços à obtenção de lucros financeiros, deixando atividades produtivas em segundo plano (LAZONICK, 2013). Esse comportamento tem impactado no mercado de trabalho, reduzindo a criação de vagas e fragilizando a situação dos trabalhadores (LAPAVITSAS, 2009).

Essa relação entre a ascensão da estratégia de MSV, a financeirização e a perda de dinamismo no mercado de trabalho tem sido crescentemente retratada pela literatura (LAZONICK; O'SULLIVAN, 2000; STOCKHAMMER, 2004; LAZONICK, 2013), sendo esse o foco deste artigo.Desse modo, o objetivo deste artigo é investigar uma amostra de empresas não financeiras de capital aberto que atuaram no Brasil entre os anos 1997 e 2013 e verificar se adotaram a estratégia MSV.

Não obstante a relevância desse tema em escala internacional, poucos trabalhos se propuseram a tratar desse tópico em relaçãoà economia brasileira. Em particular não há, salve engano, nenhum trabalho que investigue empiricamente os efeitos do MSV sobre emprego no Brasil. Isso se dá tanto pelas características dos mercados no país, quanto pela limitação de fontes de dados.Dessa forma, este artigo pretende preencher tais lacunas, ajudando a fomentar o debate sobre MSV.

1 A seção 2 discutirá em maiores detalhes esse conceito. 
Para atingir esse objetivo, será analisada uma amostra com 79empresas nãofinanceiras de capital aberto que operaram no Brasil entre os anos de 1997 a 2013. Esses dados foram obtidos do software Economatica, o qual apresenta o balanço patrimonial e a demonstração do resultado do exercício (DRE) das empresas que fazem parte da bolsa de ações brasileira. Essas demonstrações contábeis permitirão que analisemos rubricas relativas tanto ao setor financeiro quanto ao setor produtivo. A dinâmica de funcionamento dessas firmas será investigada por meio de indicadores dos setores produtivo e financeiro (imobilizado/ativo total, dividendos/lucro líquido, receita financeira/ativo total, entre outros), dando-se destaque às possíveis características relativas ao processo de financeirização. Feito isso, um modelo econométrico é construído utilizando-se a teoria da reação em cadeia (CRT)(GONZÁLEZ; SALA, 2014), com o objetivo de verificar o impacto da distribuição de dividendos (via MSV) dessas firmas sobre o emprego em setores econômicos respectivos. O método de mínimos quadrados em dois estágios é usado para estimar a relação entre o MSV, o investimento e o emprego setorial.

Os resultados econométricos confirmam a hipótese do impacto negativo da distribuição de dividendos sobre o emprego, evidenciando a financeirização das empresas da amostra, uma vez que tal correlação é apontada pela literatura como uma das características desse processo (GONZÁLEZ;SALA, 2014). Os efeitos são analisados por meio do papel intermediador do investimento: em um primeiro estágio, o pagamento de dividendos reduz o investimento das empresas. No segundo estágio, o impacto do investimento é estimado sobre o emprego. Entretanto, é possível afirmar que são fracos os indícios do uso do canal financeiro para fins estritamente especulativos, não só porque são relativamente baixos os volumes de recursos das empresas da amostra circulando no canal financeiro (em relação ao canal produtivo), mas porque as empresas apresentaram prejuízos financeiros ao longo do período. Como será discutido, esses fatos indicam que a busca de recursos externos tinha o propósito de ampliar o leque de fontes de financiamento disponíveis, em um período de alta liquidez internacional, que serviriam para sustentar o nível de produção e investimento das empresas no país. Ademais, essas característicasapontam para uma financeirização singular da economia brasileira, moldada pelo seu ambiente institucional. Esses efeitos foram analisados a partir da análise quantitativa e qualitativa dos dados, em especial as fontes de receitas e despesas financeiras das empresas, que serão melhor detalhadas na seção 3.2.

Este artigo se divide em mais quatro seções, além desta breve introdução:a seção 2 discute arranjos econômicos institucionais centrados no sistema financeiro e, em seguida,analisa a literatura internacional e delimita os termos financeirização e MSV; a seção 3analisa o desenvolvimento histórico das finanças no Brasil e, depois, a dinâmica econômico-financeira de 79 empresas não financeiras de capital aberto entre 1997 e 2013; a seção 4 apresentao estudo econométrico utilizando 
a CRT e o método de mínimos quadrados em dois estágios para estimar impactos da distribuição de dividendos sobre o emprego nos setores das firmas selecionadas; e, por fim, a seção 5 tece algumas considerações finais.

\section{Arranjos Institucionais, Sistemas Financeiros e Financeirização}

Essa seção irá descrever brevemente diferentes tipos de regimes financeiros (Subseção 2.1) e, posteriormente, se concentrar na definição de financeirização (Subseção 2.2). Será percebido que o termo financeirização comporta diferentes conotações, sendo a estratégia de maximizing shareholder value a utilizada nesse artigo.

\subsection{Arranjos Financeiros e Financeirização}

Tendo-se em vista as peculiaridades de cada economia, suas instituições, cultura, geografia, história, entre outros fatores, torna-se analiticamente oportuno agrupar determinados países em regimes institucionais, uma vez que essa diversidade indica diferentes e significantes formas de interação dos agentes econômicos, em especial nos mercados financeiros. Dessa forma, e considerando-se a proposta deste artigo, é razoável indicar as características de sistemas financeiros em diferentes países, uma vez que as relações empreendidas neles indicam o grau e sentido da interação entre o sistema financeiro e produtivo em cada país e internacionalmente. A partir dessa análise, é possível indicar não só a lógica de atuação dos agentes financeiros, mas também o grau de financeirização de cada economia, permitindo estabelecer diferenças entre diversos países.

Para esse propósito, é possível partir do trabalho de Zysman (1983), que analisa os arranjos do sistema financeiro e classifica o ambiente econômico de economias avançadas (Alemanha, Japão, França, Estados Unidose Reino Unido). Em geral, a classificação dos sistemas financeiros de Zysman (1983) serviu o propósito de definir, a partir do conjunto de agentes e estrutura financeira, qual o melhor arranjo para uma intermediação financeira eficiente (que proporcionam menores custos de transação). Os arranjos foram, inicialmente, compreendidos em dois blocos: o primeiro representa as economias nas quais o mercado de capitais são mais desenvolvidos (Estados Unidose Reino Unido) e o segundo é aquele no qual os bancos possuem maior relevância para o financiamento industrial, sendo baseado nos mercados de empréstimos de médio e longo prazo (Alemanha, Japão e França).

Jaconis (2014) discute a contemporaneidade dessa classificação em um contexto de financeirização. A autora afirma que uma análise mais atual deve levar em consideração a análise da governança corporativa e seus efeitos sobre o com- 
portamento das firmas. Desse modo, dois modelos de interação firma-mercado financeiro deveriam ser considerados: o stakeholder model e o maximizing shareholder value model. Em ambos os modelos, os acionistas têm a função, em geral, de monitorar as práticas da empresa e exigir que seus objetivos sejam alcançados a cada período. Esses objetivos divergem entre os acionistas, sendo que aqueles que concentram a propriedade das ações invariavelmente possuem mais poder para guiar as decisões da empresa. No stakeholder model, a distribuição da propriedade da empresa é mais concentrada em poucos acionistas e a governança da empresa é usualmente compartilhada, o que sustenta planos de negócios com objetivos traçados em comum acordo. No MSV, a propriedade é mais dispersa, o que inviabiliza o controle acionário, requerendo um plano de negócios mais geral que atenda a todos. Esse plano consiste em maximizar o valor da ação, promovendo ganho financeiro para seus acionistas, seja em longo ou curto período de tempo. É possível, ainda, caracterizar os modelos em sua forma de intermediação: no stakeholder model, os bancos são os principais agentes fornecendo financiamento para firmas, priorizando investimentos de longo prazo e com participação societária concentrada - no tocante à firma; no MSV, a propriedade das empresas é usualmente mais dispersa e o financiamento ocorre via mercado de capitais através da emissão de ações. Sob essas condições, os gerentes enfatizam a remuneração de acionistas no curto prazo, com impactos negativos na acumulação de capital de longo prazo.

Relacionando-se a divisão de Zysman (1983) com os canais de financeirização apontados por Jaconis (2014), poderíamos esperar que os Estados Unidos e o Reino Unido apresentassem um modelo mais próximo do MSV, enquanto os sistemas na Alemanha e França seriam melhor compreendidos a partir do stakeholder model. Entretanto, é possível classificar mercados financeiros de diferentes formas de acordo com o grau de desenvolvimento e a proximidade de suas instituições com um ou outro modelo, inclusive com perspectivas de análise híbrida, que reúne características dos dois modelos. Assim, a classificação torna possível não só indicar o grau de financeirização de diferentes economias a partir da presença de certas instituições e relações financeiras, mas também compreender o quanto a financeirização atua em prol do financiamento produtivo. Por exemplo, de acordo com Detzer e Hein (2014), a Alemanha apresenta um sistema financeiro baseado em bancos. O mercado acionário, embora existente, tem um papel secundário no financiamento. Todavia, o país, na década de 1990, adotou políticas que incentivaram o desenvolvimento de mercados acionários, impulsionando a financeirização nos moldes das economias anglo-saxônicas, isto é, promovendo o MSV. Porém, como mostra Stockhammer (2004), a financeirização, definida como estratégia MSV, não logrou qualquer efeito sobre o investimento produtivo no caso da Alemanha, diferentemente dos outros países analisados (Estados Unidos, Reino Unido e França). 
Os estudos de financeirização para países em desenvolvimento, entretanto, sinalizam que "[...] [f]inancialization is [...] not a linear process and assumes different forms in developing countries vis-à-vis advanced economies, as well as country-specific forms [...]" (BONIZZI, 2013, p. 85). Alguns fatos são elementares em processos de financeirização em países em desenvolvimento: a) firmas crescentemente realizam investimentos financeiros ao invés de produtivos, incluindo especulação em derivativos; b) há mudanças significativas no setor financeiro, incluindo expansão dos mercados de capitais (integrando o aprofundamento do sistema em direção ao modelo anglo-saxônico), mudança do papel dos bancos, que priorizam operações de securitização, corretagem e seguros e redirecionam empréstimos às famílias (setor imobiliário e microfinanças), crescimento do número de bancos estrangeiros e investidores institucionais (fundos mútuos e fundos soberanos de riqueza), privatização de políticas sociais (pensões e seguros) e financeirização de commodities (derivativos e contratos futuros que seguem ciclos financeiros de boom and bust (BONIZZI, 2013).

Portanto, em consonância com o arranjo do sistema financeiro e o ambiente institucional, países emergentes e em desenvolvimento apresentam diferentes processos de financeirização. Isso evidencia a importância de entender o arranjo institucional financeiro de forma mais detalhada, definindo os contornos de processos e relações financeiras e, em especial, a financeirização, já que pode ser entendida, de forma geral, como o aumento da significância dos motivos, relações e agentes financeiros. Ademais, a compreensão do grau de financeirização deve ser seguida da análise de suas funções, que podem tanto ser promotoras do crescimento econômico e da democratização das finanças (ERTURK et al., 2007) quanto inibidoras (BOYER, 2000; CHESNAIS, 2002), caso predominem transações no circuito financeiro que visem os lucros financeiros (em oposição aos retornos advindos do processo produtivo). Um dos objetivos deste artigo é oferecer evidências dos efeitos da financeirização para o caso do Brasil.

O Gráfico 1 retrata o valor de capitalização de mercado (preço da ação multiplicado pela quantidade de ações) dividido pelo PIB em quatro diferentes países. Essa medida serve como uma proxy para o grau de desenvolvimento do mercado acionário nesses países (TRIDICO; PARIBONI, 2018; JACONIS, 2014) e, portanto, pode indicar diferenças entre os graus de financeirização entre países. No Gráfico 1 é possível ver que os Estados Unidose o Reino Unido apresentam os maiores valores médios de capitalização entre 1975 e 2013 (respectivamente, $112 \%$ e 52\%), seguidos por Alemanha e Brasil (respectivamente, 32\% e 14\%). 
Gráfico 1 - Capitalização de mercado (em porcentagem)

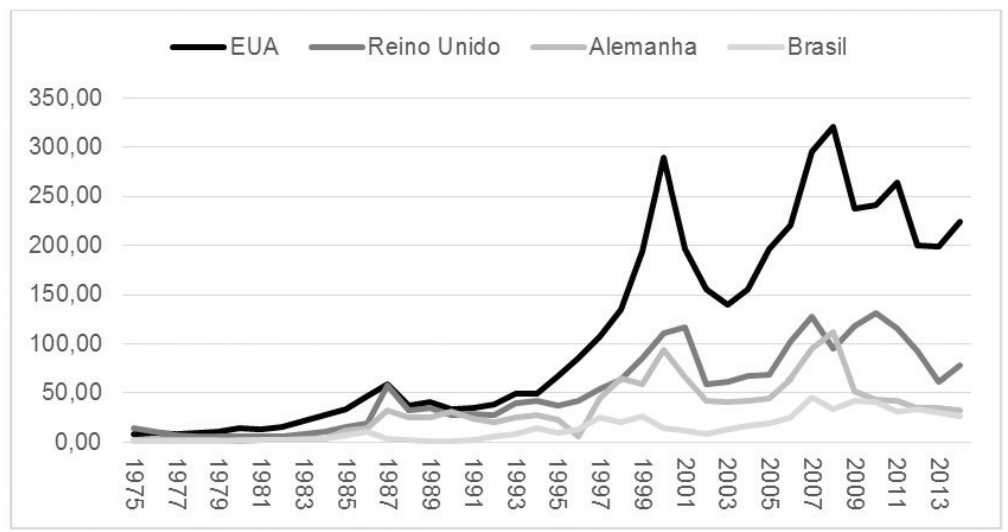

Fonte: Elaboração própria a partir de dados do Banco Mundial

Em relação ao Brasil, a literatura indica um mercado de capitais pouco desenvolvido (GUERRA, 2002; VIEIRA, 2002; SANT'ANNA, 2009). Ademais, a interação entre indústria, governo e mercado financeiro, marcada pelo intervencionismo público, nos aproxima de um arranjo financeiro baseado no crédito bancário (PINTO; GONÇALVES, 2015). A esse cenário, aliam-se altas taxas de juros, que condicionam a atuação dos agentes financeiros e a extração de renda. Essas características suscitam a discussão do tipo de financeirizaçãoao qual a economia brasileira está submetida. Entretanto, antes de analisarmos com mais detalhes o grau de financeirização da economia brasileira e seus efeitos sobre as relações produtivas, faz-se necessária uma breve discussão sobre o conceito de financeirização a ser utilizado e a contextualização do caso brasileiro.

\subsection{Financeirização e Maximizing Shareholder Value}

O termo financeirização não possui uma definição exata, sendo um conceito que comporta diferentes traços que consubstanciam tal fenômeno. A definição de financeirização utilizada nesta seção se baseará no trabalho de Van der Zwan (2014), o qual dialoga com a visão da teoria da regulação sobre esse processo. ${ }^{2}$ Segundo Van der Zwan (2014), o conceito de financeirização pode ser elucidado como elemento de um novo regime de acumulação, por onde se alteram os planos de diferentes agentes econômicos, como o MSV, e como um processo mais amplo, de financeirização da vida cotidiana.Vale ressaltar que essa definição de financeirização é concernente às economias anglo-saxônicas.

2 Ver também Chesnais (2002). 
Esta última abordagem, mais ampla, retrata a influência das finanças sobre a vida cotidiana dos indivíduos, em que o grau de financeirização representa a participação das famílias nos mercados financeiros. Para Erturk et al. (2007), esse processo indica a democratização das finanças, pelo qual indivíduos de classe de renda média e baixa, antes excluídos, acessariam o sistema financeiro motivados pela possibilidade de ganhos de renda e pela percepção tácita de que conseguiriam administrar os riscos advindos da posse de ativos financeiros. Decisões relativas à aposentadoria, consumo, lazer e educação passam a ser tomadas com base nas disponibilidades oferecidas pelo mercado financeiro (LAPAVITSAS, 2011). A vida social e individual do cidadão comum se transforma sob a influência das finanças e a evolução do ciclo de vida se torna cada vez mais financeirizada. ${ }^{3}$

Por outro lado, a teoria da regulação analisa a financeirização como um regime sucessor do Fordismo. Boyer (2000) destaca a importância do mercado financeiro em regimes de acumulação crescentemente financeirizados, atuando não somente sobre a concorrência entre empresas e indivíduos, mas também alterando a própria atuação do Estado,que passa a integrar esse novo enfoque na medida em que ajusta-se aos critérios dos mercados financeiros para administrar suas finanças. O lucro financeiro passa a ser uma importante variável para mensurar o rendimento das instituições, sejam elas públicas ou privadas. Nessa abordagem, as finanças conduzem o processo de acumulação de capital.

Desde o fim da Segunda Guerra Mundial, as firmas e corporações não financeiras foram caracterizadas pela autonomia operacional dos gerentes e direcionamento do capital para empreendimentos de longo prazo, gerando maior produção e número de empregos, distribuição mais igualitária dos ganhos de produtividade para os trabalhadores e reduzida influência das finanças sobre suas decisões (CHANDLER, 1977; BOYER, 2000). Esse quadro é modificado nos anos 1970 e 1980, principalmente dado o quadro de deterioração econômica, aumentos de preços e internacionalização dos mercados. De acordo com Lazonick e O'Sullivan (2000), conforme as firmas deparavam-se com o aumento da competição externa e a redução da lucratividade, a prática de MSV surgiu para tentar contornar esse quadro, sendo vista como um mecanismo eficiente, em um contexto de liberalização de mercados, ${ }^{4}$ para fortalecer o desempenho das empresas. Tal estratégia é explicada pela teoria do agente principal, na qual existe uma relação em que uma parte (o principal) gostaria que outra parte (o agente) agisse

3 Não é o foco deste artigo fazer uma descrição mais longa dos traços da financeirização, como a proliferação do rentismo e a expropriação financeira, os quais podem ser vistos nos trabalhos de Palley (2013), Lucarelli (2012), Krippner (2005) e Lapavitsas (2009).

4

Plihon (2005) trata da relação entre políticas de abertura econômica e a ascensão das finanças. O autor explicita como ocorreu a penetração das finanças internacionais sobre empresas domésticas, em especial, na França. Um ponto importante é observar que a governança corporativa emergiu em meio a esse processo. 
de alguma forma ou detivesse algum atributo que é de interesse do principal, mas que não pode ser exigido ou garantido plenamente por um contrato. O problema fundamental é que existe um conflito de interesses e a informação disponível não permite que o principal escreva um contrato executável que garanta que obterá o que quer da interação com o agente (LAZONICK; O'SULLIVAN, 2000; MIRANDA, 2013).

A convergência entre os interesses dos gerentes e dos acionistas ocorreria com a alteração na estrutura de incentivos aos primeiros, ou seja, permitindo que o pagamento dos gerentes passasse a contar com opções de compra de ações da própria empresa, além de outros bônus (STOCKHAMMER, 2004). Ao mesmo tempo, o próprio aumento no pagamento de dividendos para os acionistas acarretava a valorização das ações da empresa, uma vez que atraía novos investidores e confirmava as expectativas do mercado financeiro (LAZONICK, 2013). Desse modo, gerou-se a união de interesses entre gerentes e acionistas pela valorização das ações da empresa.

De fato, é possível inferir que tal estratégia logrou frutos na década de 1990, seguindo a expansão da economia americana e da liquidez internacional na onda dos desenvolvimentos das tecnologias de informação, inclusive aprofundando o processo de financeirização, especialmente em economias desenvolvidas. Desde então, independentemente da fase do ciclo econômico, diversas empresas não financeiras têm se engajado na prática de recompras de ações, aquisição de ativos financeiros e maior distribuição de dividendos (CROTTY, 2003). Isso representou o deslocamento parcial da fonte de acumulação de capital do setor produtivo para o setor financeiro, causando a desaceleração do investimento em produção, com impactos negativos sobre o emprego e o mercado de trabalho (GONZÁLEZ; SALA, 2014).

Uma evidência da relação entre o MSV, o investimento produtivo e o emprego pode ser vista em González e Sala (2014). Os autores analisam a economia dos Estados Unidos entre os anos 1960 e 2009 através de um modelo empírico de três estágios e, em um primeiro momento, os resultados econométricos indicaram uma relação negativa entre o MSV e a acumulação de capital. Posteriormente, a acumulação de capital se mostrou relacionada - de forma negativa - com a taxa de desemprego. Uma das conclusões foi que uma expansão mais lenta do investimento produtivo tende a prejudicar o emprego.

Destarte, a estratégia das empresas não financeiras de capital aberto em elevar a remuneração dos acionistas e o valor de suas ações apresenta a contrapartida em reduzir investimentos produtivos, uma vez que parte dos recursos são deslocados para o setor financeiro. Subjacente a essa modificação está a desaceleração na criação de postos de trabalho, redução na remuneração dos trabalhadores ou precarização das condições de trabalho. Em resumo, a empresa adota medidas 
para reduzir os custos produtivos, em geral, e trabalhistas, em particular, para que consiga se adequar às exigências do mercado financeiro. No tocante à financeirização, as três definições apresentadas partem do princípio que o setor produtivo é afetado negativamente na medida em que a esfera financeira assume um papel antagônico à esfera produtiva, dissociando-se desta e assumindo um caráter autônomo na acumulação de capital.

\section{Financeirização e a Economia Brasileira}

Explicitado o termo financeirização (Seção 2), essa seção analisa o aumento da participação do capital financeiro na economia brasileira (Subseção 3.1) e investiga o comportamento das empresas da amostra entre os anos 1997 e 2013 (Subseção 3.2).

\subsection{Crescimento da Importância das Estratégias Financeiras no Brasil}

É notório que, a partir dos anos 1980, após os impactos dos choques do petróleo, do choque de Volcker (1979-1982) e da desaceleração da economia mundial, o Brasil passou a conviver com recorrentes déficits comerciais e aumento das necessidades de financiamento que, aliados à crescente inflação, trouxeram a dívida pública para o eixo central da administração pública (HERMANN, 2016). A esse fator, somava-se um mercado financeiro pouco desenvolvido e de baixo grau de abertura, o que limitava os canais de financiamento existentes e amplificava os impactos dos choques internacionais no país. É possível afirmar que o país implementou as políticas do Consenso de Washington de forma parcial e mais gradual que outros países latino-americanos (BONIZZI, 2013), sob um regime monetário e financeiro que conduzia um processo de financeirização baseado em um sistema monetário dual: ao lado da moeda emitida pelo Estado, sujeita à corrosão inflacionária, uma moeda alternativa era emitida pelo setor financeiro, garantida pela dívida pública e indexada pela inflação, permitindo a acumulação de capital por instituições financeiras privadas (ARAÚJO; BRUNO; PIMENTEL, 2012). Em relação ao mercado de trabalho, a crescente inflação e a queda do crescimento econômico impactaram de forma adversa os trabalhadores: aumento do desemprego, queda do rendimento real médio, aumento da desigualdade de renda e crescimento da informalidade (ARANDIA, 1991).

Na década seguinte, a privatização de estatais, a abertura comercial e financeira e uma reforma tributária foram realizadas para tentar reverter o quadro de estagnação econômica do país (GARAGORRY, 2007). Essas medidas resultaram, entre outras coisas, na redução da participação do governo na esfera econômica, bem como havia ocorrido em outros Estados nacionais durante os anos 1970 e 
1980. Adicionalmente, na primeira metade da década de 1990 o Plano Real é implementado, encerrando longo período de convívio com alta inflação, mas também aprofundando o endividamento interno e externo do país (PAULANI, 2013). De uma forma geral, a taxa de desemprego apresentou tendência crescente em todo o período (RAMOS; BRITTO, 2004). A informalidade também aumentou, apresentando recuo somente a partir do ano de 2000.

De acordo com Belluzzo e Almeida (2002), que analisam a economia brasileira nas décadas de 1980 e 1990, as empresas privadas utilizaram duas estratégias para reduzir a fragilidade financeira em meio a esse contexto: redução do endividamento e uso de markups. O aumento da taxa de juros interna e a redução do prazo dos títulos públicos fizeram com que essas firmas transferissem considerável parte de seu capital para a posse de ativos do Estado, resultando no aumento de aplicações financeiras em ativos e títulos do setor público. Concomitantemente, tanto o lucro operacional quanto o lucro financeiro aumentaram, o que pode ser explicado pelo aumento dos markups, no primeiro caso, e pelas aplicações financeiras, no segundo caso. A financeirização nesse período e a acumulação de capital, portanto, foram estimuladas por altas taxas de juros, com redistribuição da renda da classe média para o capital financeiro (BONIZZI, 2013).

Zonenschain (1998) denota que as empresas de capital aberto utilizaram precipuamente o lucro retido para autofinanciamento entre os anos de 1989 e 1996 , não obstante o endividamento por intermédio da obtenção de recursos do Banco Nacional de Desenvolvimento Econômico e Social (BNDES) (MADEIRA, 2013). Júnior (2007) também ressalta que, de 1996 a 2004, as empresas não financeiras aumentaram o uso de derivativos cambiais, muito em virtude da busca por maior proteção devido ao risco de desvalorização cambial e ao agravamento das dívidas em moeda externa.

O período a partir do ano de 2004 representa uma inflexão na trajetória da economia brasileira em termos de crescimento. Os preços das commodities nos mercados internacionais crescem com o aumento da demanda por parte de países emergentes, como a China e a Índia, e a liquidez externa é abundante. O Brasil se aproveita desse ambiente econômico e apresenta significativo crescimento do PIB (BALTAR, 2011). A respeito das empresas não financeiras de capital aberto, de acordo com Filleti (2010) estas alteraram seu padrão de financiamento no decorrer dos anos 2000: o autofinanciamento foi predominante entre 2003 e 2005 , perdendo espaço para uma estratégia de endividamento na segunda metade da década. É interessante afirmar que, embora a autora tenha separado o período analisado em dois, em ambos o financiamento pela emissão de ações foi a fonte menos utilizada pelas empresas, o que possivelmente indica um ambiente institucional brasileiro relativamente diferente de outros países (ver Gráfico 1), como 
o das economias anglo-saxônicas, que, portanto, sugere cautela ao se analisar os traços institucionais da financeirização no Brasil.

Analisando as empresas não financeiras de capital aberto entre os anos de 1995 e 2012, Miranda (2013) conclui que aprofundaram o uso da governança corporativa do tipo MSV. De acordo com o autor, o deslocamento do capital para aumentar a distribuição de dividendos, bem como a busca de lucro no curto prazo seriam fatores que corroborariam sua tese. Ademais, a redução do investimento dessas firmas, juntamente com o aumento da liquidez, são também fatores que evidenciam a maior relação entre o MSV e os mercados financeiros. Em relação ao mercado de trabalho, em especial no período de 2004 a 2008, o emprego formal cresceu e os salários reais médios aumentaram (BALTAR, 2011). Fatores como o boom das commodities, liquidez internacional e crescimento econômico contribuíram para fomentar o emprego no país. A política econômica do governo foi em geral marcada pela preservaçãodo mercado de trabalho, a despeito da piora de alguns indicadores econômicos nos últimos anos (BALTAR, 2011).

Para fins deste estudo, ainda é possível argumentar que nos anos recentes o mercado de trabalho apresentou melhoras em seus indicadores, ao passo que as empresas, segundo Miranda, Crocco e Santos (2017), intensificaram o uso da estratégia de MSV. Os autores supõem que com o avanço da financeirização no paíssob impulsos do aumento do financiamento público por meio de títulos públicos com elevada remuneração e liquidez - a estratégia MSV se tornou mais relevante, uma vez que a alta remuneração e liquidez dos títulos soberanos serviam de base para ampliar as receitas financeiras de todos os tipos de empresas. Adicionam-se a essa tendência as políticas de abertura financeira empreendidas na década de 1990, as quais propiciaram maior capacidade de endividamento externo sob condições internacionais favoráveis. Consequentemente, empresas não financeiras poderiam utilizar esse tipo de endividamento - como de fato fizeram - para realizarem suas operações (FILLETI, 2010). A maior proximidade de empresas nãofinanceiras de capital aberto com o mercado financeiro em geral, conforme discutido na revisão de literatura, é uma condição fundamental para a ascensão da estratégia MSV - inclusive no Brasil (MIRANDA; CROCCO; SANTOS,2017). As próximas seções investigam com mais cuidado essa relação.

\subsection{Análise das Empresas nãoFinanceiras de Capital Aberto no Brasil}

Para realizar a investigação proposta neste estudo, 79 empresas nãofinanceiras que participam da Bovespa compreendidas em 14 setores da economia são analisadas no decorrer desta seção. ${ }^{5}$ A maioria dos dados, deflacionados pelo Índice de Preços ao Consumidor Amplo (IPCA), base 2015, foram obtidosdo software

5 A lista de empresas e seus respectivos setores são apresentados no Anexo A (Tabela 5). 
Economatica para o período de 1997 a 2013. Essa amostra inicial de empresas foi selecionada levando em consideração o conjunto máximo de informações consistentes possível. ${ }^{6}$ Sobre este, tentou-se ser o mais abrangente possível. Todavia, a escassez de dados impediu que uma série mais longa pudesse ser utilizada. Por fim, os dados se referem ao quarto trimestre de cada ano. A Tabela 6 (ver Anexo A) resume as variáveis utilizadas na análise.

Os Gráficos 2 e 3 exibem, respectivamente, o imobilizado/ativo total e a distribuição de dividendos. No Gráfico 2, a proporção imobilizado/ativo total apresenta uma tendência cíclica ao longo de todo o período. De 1997 a 2002 o seu patamar médio cai, mas se recuperaentre 2003 e 2009, sendo que a crise financeira interrompe ligeiramente esse movimento. Esses dados mostram que, nos primeiros seis anos da série, a acumulação de capital das empresas se reduziu em proporção ao ativo total, em consonância com Miranda (2013). Ademais, é visível também o efeito sobre o imobilizado/ativo total dos anos de expansão da economia brasileira.

Gráfico 2 - Imobilizado/ativo total

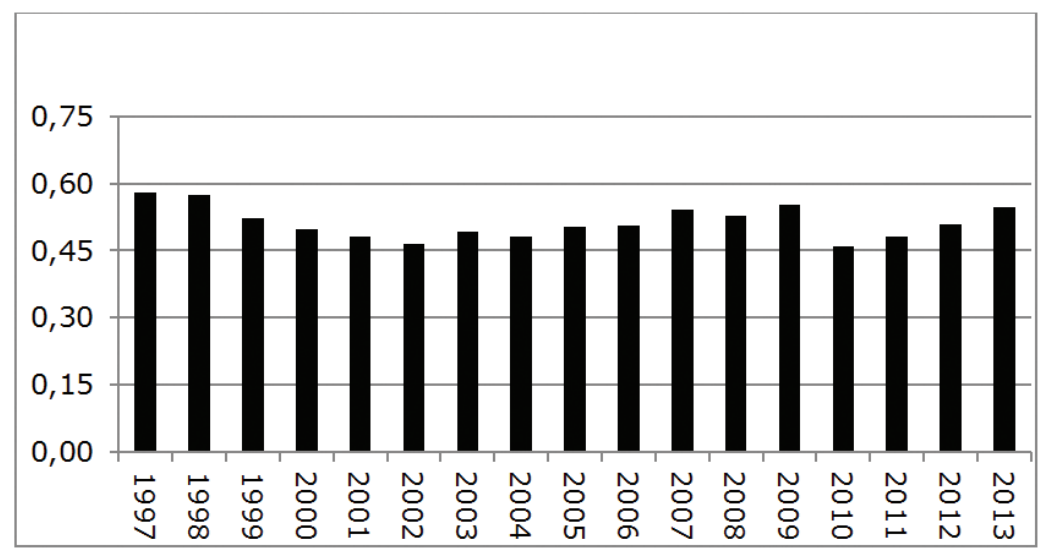

Fonte: Elaboração própria a partir de dados do Economatica

Paralelamente, por meio do Gráfico 3, pode-se perceber a crescente distribuição de dividendos dessa amostra de firmas. Em termos da relação entre MSV e investimento, é possível inferir quea grande expansão da distribuição de dividendos se deu exatamente no período pós-2002 de ascensão do ciclo de investimento.

6 O número de empresas na amostra é estritamente definido pela disponibilidade de informações de distribuição de dividendos no período entre 1997 e 2013, sendo que empresas que possuíam pouca ou nenhuma informação foram descartadas da amostra. 
Gráfico 3 - Distribuição de dividendos em milhares de reais

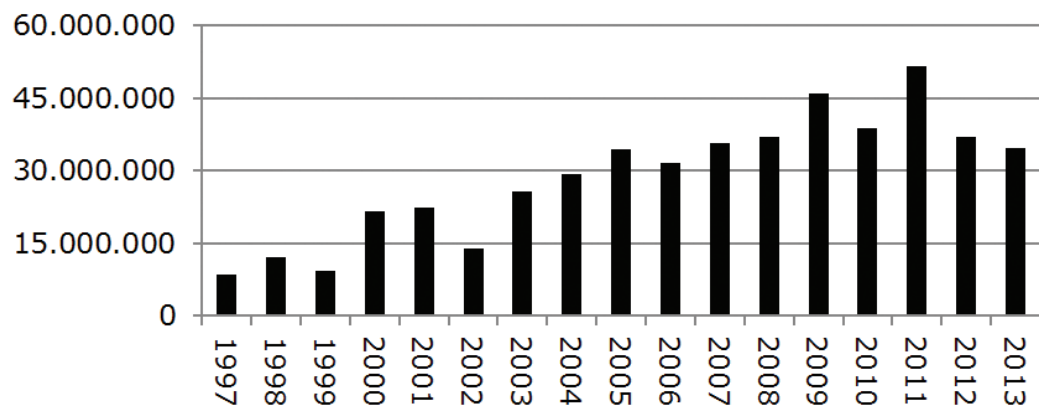

Fonte: Elaboração própria a partir de dados do Economatica

Comparativamente às experiências internacionais, Lazonick e O'Sullivan (2000) analisam empresas de capital aberto dos Estados Unidos entre os anos 1960 e 1998 e apontam que o valor médio do pagamento de dividendos em proporção ao lucro líquido foi de 50\%. Já Lazonick (2013) indica que, para 292 empresas de capital aberto dos Estados Unidos (1981 a 2007), tal proporção girou entre 40 e $50 \%$. O caso brasileiro pode ser visto no Gráfico 4.

Gráfico 4 - Dividendos/lucro líquido (em porcentagem)

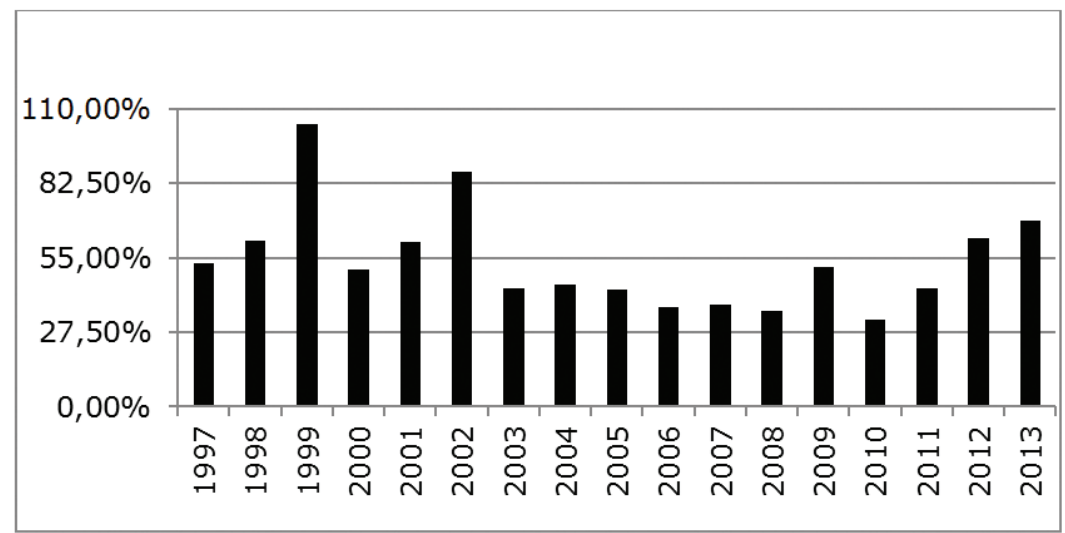

Fonte: Elaboração própria a partir de dados do Economatica

Assim como nos trabalhos de Lazonick (2013) e Lazonick e O'Sullivan (2000), a proporção dividendos/lucro líquido no Brasil variou em torno de 45\%. Portanto, a proporção de recursos destinada à remuneração dos acionistas não é tão diferente da vista nos Estados Unidos. O que se pode destacar no Gráfico 4, entretanto, é a relativamente baixa proporção dividendos/lucro líquido entre 2003 
e 2011 comparativamente ao período de 1997 a 2002. Se compararmos tais dados à distribuição de dividendos (Gráfico 3), é perceptível que este aumentou proporcionalmente ao lucro, entre 1997 e 2002, diferentemente do período posterior, no qual tanto o lucro quanto a distribuição de dividendos aumentaram proporcionalmente. Portanto, é concebível descrever duas fases no período de análise: nos primeiros seis anos, há redução do lucro e da acumulação de capital, mas alta relativa de distribuição de dividendos; a partir de 2003, aumentam investimento, lucros e dividendos distribuídos.

Com o objetivo de se aprofundar a compreensão da geração de dividendos e o comportamento das firmas selecionadas, a Tabela 1 resume a dinâmica intertemporal de alguns indicadores. As quatro primeiras linhas da tabela, referentes às relações entre receita operacional, $\mathrm{RO}$ (receita com a venda de produtos e mercadorias e a prestação de serviços, ou seja, é a receita obtida através do setor produtivo), receita financeira, $\mathrm{RF}$ (receita com juros recebidos, descontos obtidos e com rendimentos nominais de aplicações financeiras, ou seja, é a receita obtida através do setor financeiro), ${ }^{7}$ lucro retido, LR (lucro apropriado pela empresa para atender a outras finalidades, como o autofinanciamento) e ativo total (AT) indicam que o setor produtivo foi a fonte geradora da maior parte das receitas das empresas. É possível afirmar também que o lucro retido aumentou relativamente os ativos das empresas. Entretanto, as receitas financeiras (juros obtidos e receitas de aplicações financeiras) se reduzem relativamente ao ativo total, em especial entre 2003 e 2013, o que fica claro também na proporção entre receitas financeiras e operacionais. Em termos de estratégia MSV e de financeirização, era de se esperar que, caso tal processo fosse similar com a experiência internacional- em especial, às economias anglo-saxônicas-, o setor financeiro estaria à frente da dinâmica de geração de receitas, ou pelo menos apresentasse crescente participação. Portanto, a financeirização, no caso brasileiro, apresenta traços singulares, circunscritos ao ambiente institucional que a modela.

7 Tanto as receitas quanto as despesas financeiras foram obtidas da Demonstração de Resultados do Exercício e dizem respeito a todas as operações financeiras das empresas. 


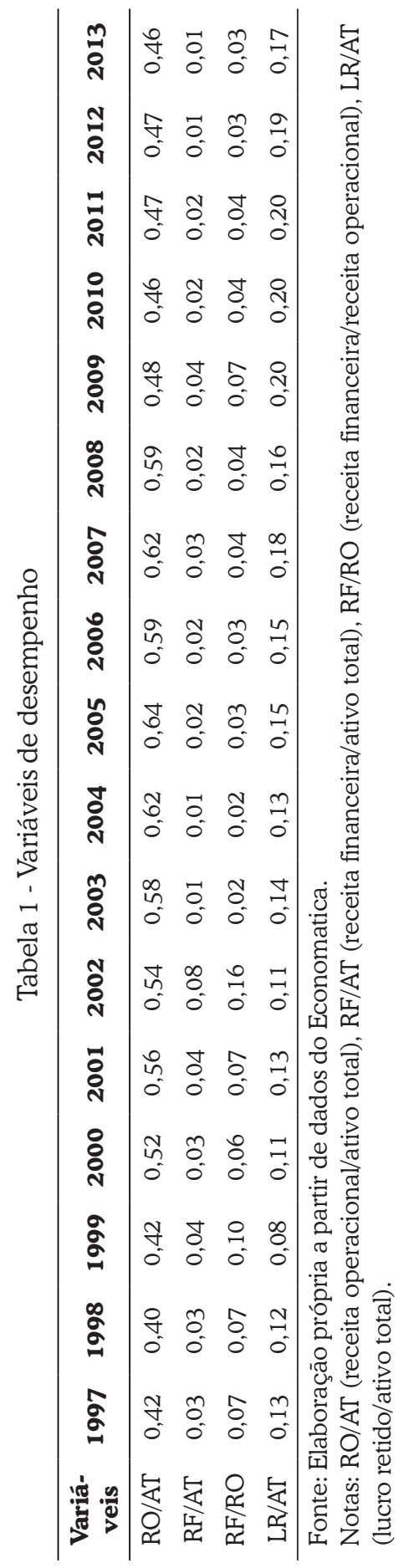


Para se aprofundar a questão sobre a singularidade da financeirização do Brasil, a Tabela 2 retrata dados relativos ao lucro e ao setor financeiro. Em relação à Tabela 1, acrescentaremos as rubricas lucro nãofinanceiro, LNF (diferença entre receita operacional e despesa operacional), lucro financeiro, LF (diferença entre receita financeira e despesa financeira), despesa financeira, DF (despesa com o pagamento de juros e de variações monetárias e/ou cambiais), receita de aplicações financeiras, RA (receita de rendimentos nominais de ativos financeiros), receita ou despesa com variações cambiais e/ou monetárias, VCM (receita ou despesa advinda da oscilação do câmbio e/ou moeda sobre ativos e operações financeiras) e encargos de operações financeiras, $\mathrm{EF}$ (despesa financeira com exceção da despesa com a variação cambial e/ou monetária. Uma análise mais detalhada dos lucros da amostra de empresas mostra que, em geral, operaram com prejuízo financeiro em todo o período (LF), enquanto os lucros não financeiros tiveram significativo aumento (LNF). Estes sobem, segundo dados do Economatica (2013), de $R \$ 51$ bi, em 2002, para 170 bi, em 2011, pari passu ao aumento das despesas financeiras, especialmente as relativas às despesas com juros (MIRANDA, 2013). Assim, duas características da financeirização dessa amostra podem ser elencadas. A primeira se refere ao protagonismo do setor produtivo na geração de receitas e na viabilidade econômica das empresas. O segundo é o papel do setor financeiro, funcionando, muito provavelmente, como financiador das atividades produtivas. A hipótese de obtenção de receita por meio da especulação nos mercados financeiros se enfraquece frente aos dados da Tabela 2, que exibem despesas financeiras sempre superiores às receitas financeiras, culminando em seguidos prejuízos financeiros. 


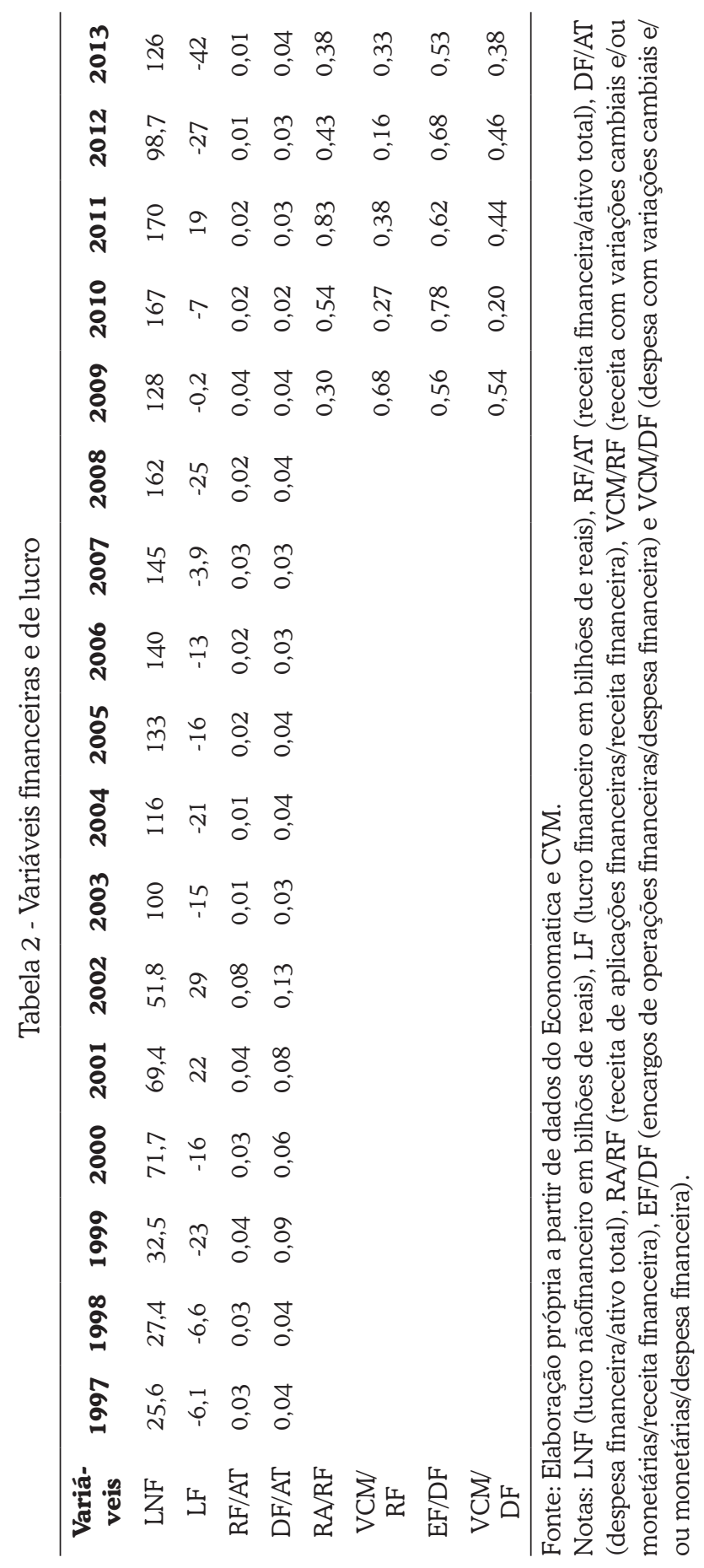


As últimas quatro linhas da Tabela 2 indicam as principais origens das receitas e principais destinos das despesas financeiras das empresas selecionadas. Apesar da disponibilidade de informações apenas para os anos a partir de 2009, é possível auferir uma relativa importância crescente de receitas de aplicações financeiras (RA) comparativamente a receitas com variações cambiais (que indica indiretamente o uso de instrumentos de proteção cambial) e o peso relativo dos encargos financeiros de juros sobre as despesas financeiras ( $\mathrm{EF} / \mathrm{DF})$, o que pode indicar maior endividamento das empresas no período.

Em suma, pode-se inferir que o setor produtivo foi o propulsor do crescimento dessas empresas, mais que compensando os resultados financeiros negativos. O aumento da produção e do imobilizado aparentam terem sido sustentados por crescimento do endividamento das firmas, culminando em crescentes despesas financeiras. Ademais, os resultados positivos no setor produtivo possibilitaram o aumento do lucro retido em proporção ao ativo total e à crescente distribuição de dividendos (LR/AT na Tabela 1). Se considerarmos o trabalho de Orhangazi (2007), o qual analisa dois canais pelos quais a financeirização pode reduzir o investimento produtivo (oportunidades de lucro financeiro e redução do lucro retido em virtude de pagamentos financeiros), perceberemos que nenhum se fez presente na amostra de empresas analisadas. Em primeiro lugar, as empresas operaram com prejuízo financeiro em todo o período. Em segundo lugar, o lucro retido cresceu, o que foi possível, mesmo distribuindo crescentes quantidades de dividendos, por conta dos crescentes lucros do setor produtivo.

No tocante à estratégia de MSV, a dinâmica de geração de dividendos destoa da vista internacionalmente. Em economias desenvolvidas que adotam o MSV, o setor financeiro tem crescentemente proporcionado receitas que são distribuídas posteriormente na forma de dividendos, enquanto o setor produtivo perde ímpeto, acarretando a desaceleração do investimento produtivo (GONZÁLEZ; SALA, 2014).

Portanto, essas empresas adotaram a estratégia MSV, ainda que com algumas peculiaridades que não permitem afirmar que foi uma estratégia financeirizada como a vista nas economias anglo-saxônicas, todavia mostra uma financeirização modelada de acordo com o ambiente institucional brasileiro. Entretanto, essa conclusão deve ser vista com parcimônia; alguns fatores como a heterogeneidade da amostra, grau reduzido do desenvolvimento do mercado acionário (SANT'ANNA, 2009) e reduzida representatividade dessas empresas em termos da totalidade da economia brasileira evidenciam que algumas inferências devem ser vistas com cautela. 


\section{Abordagem Teórica e Empírica}

Essa seção explicita o modelo teórico de González e Sala (2014) que serviu de base para a construção do modelo econométrico. Em seguida a estratégia de estimação é apontada juntamente com a apresentação da base de dados. Por fim, discute-se os resultados das estimações.

\subsection{Modelo deReação em Cadeia (CRT)}

Essa seção descreve a CRT, que serve de base para a construção do modelo econométrico nas seções seguintes. De acordo com Karanassou e Sala (2009), a CRT se baseia em um modelo para descrever o funcionamento de um sistema econômico a partir de uma abordagem dinâmica,que visa explicar a evolução da inter-relação entre mercado de trabalho, mercado de capitais e decisões produtivas de firmas.

Para formalizar o estudo sobre variações no emprego via CRT, González e Sala (2014) apresentam três equações: ${ }^{8}$

$$
\begin{gathered}
\mathrm{n}_{\mathrm{t}}=\alpha_{1} \mathrm{n}_{\mathrm{t}-1}+\beta_{1} \mathrm{k}_{\mathrm{t}}-\gamma_{1} \mathrm{w}_{\mathrm{t}} \\
\mathrm{l}_{\mathrm{t}}=\alpha_{2} \mathrm{l}_{\mathrm{t}-1}+\beta_{2} \mathrm{z}_{\mathrm{t}} \\
\mathrm{w}_{\mathrm{t}}=\beta_{3} \mathrm{pr}_{\mathrm{t}}+\gamma_{3} \mathrm{u}_{\mathrm{t}}
\end{gathered}
$$

em que $n_{t}$ é o emprego, $k_{t}$ é o estoque de capital, $w_{t}$ é o salário real, $l_{t}$ é a força de trabalho, $z_{t}$ é a população em idade ativa, $\mathrm{pr}_{\mathrm{t}}$ é a produtividade do trabalho e $u_{t}$ é a taxa de desemprego. Os parâmetros autoregressivos $\alpha_{1}$ e $\alpha_{2}$ são positivos e menores do que um. Esses parâmetros também denotam o processo convergente

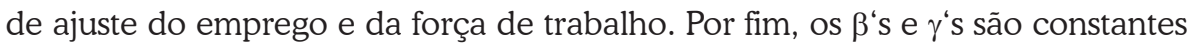
positivas.

Assume-se que o estoque de capital, salário real, produtividade do trabalho e a população em idade ativa são variáveis com taxas de crescimento que se estabilizam no longo prazo. Como todas as variáveis das equações 1, 2 e 3 estão em logaritmo, pode-se obter uma aproximação da taxa de desemprego pela diferença entre a força de trabalho e o emprego:

8 A escolha por um modelo em cadeia se faz, por um lado, pela abordagem teórica, na qual a financeirização afeta o investimento das firmas, que, em seguida, afeta a demanda de emprego. Por outro lado, um modelo mais generalista geraria problemas de endogeneidade, gerando implicações severas ao modelo econométrico. Um modelo em cadeia (dois estágios) permite lidar com tais situações diretamente. 


$$
u_{t} \cong 1_{t}-n_{t}
$$

A taxa de desemprego é estável no longo prazo se $\Delta \mathrm{u}_{\mathrm{t}}=0$, o que ocorre somente quando:

$$
\Delta \mathrm{n}_{\mathrm{t}}=\Delta \mathrm{l}_{\mathrm{t}}
$$

Como pôde ser visto na equação 1 , a variação do estoque de capital influencia o emprego que, por sua vez, interfere na equação 4, ou seja, na taxa de desemprego. Esse é o mecanismo pelo qual o investimento (taxa de crescimento do estoque de capital) impacta no desemprego utilizando a modelagem da CRT. Este artigo utiliza esse mecanismo para captar o impacto do mercado financeiro sobre o mercado de trabalho.

Procurando explicar a queda do desemprego entre os anos de 1993 e 2006 na Austrália, Karanassou e Sala (2009), por meio de estimativas econométricas, chegam à conclusão de que a acumulação de capital foi o fator primordial para a tendência observada. Para isso, a CRT foi utilizada juntamente com o método de mínimos quadrados em três estágios (MQ3E), com o investimento sendo utilizado como variável exógena na equação da demanda por trabalho. Ademais, mesmo com indicações da importância da acumulação de capital no processo, os autores não incluem nenhuma variável relativa à financeirização.

Esse padrão é abandonado na modelagem de González e Sala (2014). Abrangendo os anos de 1960 a 2009, com o arcabouço da CRT e o método de MQ3E, esses autores tentam explicar o desemprego dos Estados Unidos através da acumulação de capital, ao mesmo tempo captando os efeitos da financeirização sobre o investimento. Para realizar tal tarefa, além das equações comumente retratadas em trabalhos que usam a CRT para explorar o mercado de trabalho (equações 1, 2 e 3), eles adicionaram uma quarta equação:

$$
\Delta \mathrm{k}_{\mathrm{t}}=\alpha_{4} \Delta \mathrm{k}_{\mathrm{t}-1}+\beta_{4} \mathrm{f}_{\mathrm{t}}+\gamma_{4} \mathrm{cu}_{\mathrm{t}}+\delta_{4} \mathrm{cc}_{\mathrm{t}}
$$

em que $f_{t}$ é a financeirização, medida pela soma entre a distribuição de dividendos e o pagamento de juros dividida pelo lucro das firmas não financeiras; $\mathrm{cu}_{\mathrm{t}}$ é a capacidade utilizada; e $\mathrm{cc}_{\mathrm{t}}$ é o custo do capital. Desse modo, não obstante os autores procurarem explicar o desemprego por meio das variações da acumulação de capital, a própria acumulação de capital é explicada pela equação 6, em específico pela financeirização. González e Sala (2014) tornam endógena a variável investimento, ao contrário do trabalho de Karanassou e Sala (2009), que trata essa variável como exógena, entrando na equação de demanda de trabalho. 
Nas seções seguintes, o objetivo é estimar o impacto da distribuição de dividendos da amostra de firmas analisada na seção 3 sobre o emprego nos seus respectivos setores de atuação. Tal abordagem toma como base o modelo utilizado por González e Sala (2014) para construir um modelo econométrico em que a acumulação de capital é o principal canal entre o MSV e o emprego.

\subsection{Metodologia: Modelo Econométrico}

De acordo com a abordagem da CRT, as equações 7 e 8, a seguir, são utilizadas no modelo a ser estimado, sendo uma para a acumulação de capital e outra para o mercado de trabalho. A equação de acumulação de capital é a seguinte:

$$
\Delta \mathrm{k}_{\mathrm{it}}=\beta_{0}+\beta_{1} \Delta \mathrm{sal}_{\mathrm{st}}+\beta_{2} \text { efic }_{\mathrm{it}}+\beta_{3} \Delta \mathrm{efic}_{\mathrm{it}}+\beta_{4} \text { divluc }_{\mathrm{it}}+\beta_{5} \text { divluc }_{\mathrm{it}-1}+\mathrm{u}_{\mathrm{it}}
$$

O termo $\Delta \mathrm{k}_{\mathrm{it}}$ representa a proxy para a taxa da acumulação de capital por empresa ao longo do tempo, isto é, a diferença da razão entre imobilizado e total do ativo de cada empresa entre o período corrente e o período anterior. É a variável que denota o investimento por empresa, além de ser a variável dependente. $\Delta \mathrm{sal}_{\mathrm{st}}$ é a taxa do salário setorial; efic $_{\text {it }}$ é o nível de receitas operacionais, dado o estoque de capital por empresa, uma proxy para eficiência, enquanto $\Delta$ efic $_{i t}$ é a taxa de mudança da eficiência. A próxima variável é a divluc ${ }_{i t}$, que representa, em termos mais estritos, a estratégia de MSV por empresa. É esperado, com base em González e Sala (2014), que divluc it $_{\text {it }}$ pacte negativamente a taxa de investimento, $\Delta \mathrm{k}_{\mathrm{it}}$, na medida em que uma vez que as firmas passam a priorizar a remuneração dos acionistas em detrimento às atividades produtivas, o investimento pode ser afetado, conforme discutido nas seções 2 e 3 . Outras proxies de financeirização também serão incluídas no modelo.

A última variável explicativa no modelo é divluc $\mathrm{it}_{\mathrm{it}-1}$, que é a variável da proporção de dividendos defasada em um ano. O argumento para usá-la decorre da tentativa de captar o efeito da decisão passada de distribuição de dividendos sobre a decisão de investimento no presente. Com base na divluc $\mathrm{i}_{\mathrm{it}}$, espera-se um sinal negativo; e o último termo, , representa os erros da estimação.

A segunda equação utilizada, para estimação dos impactos sobre o emprego setorial, é a demanda por trabalho:

$$
\mathrm{emp}_{\mathrm{st}} \mathrm{pm}_{\mathrm{it}}=\alpha_{0}+\alpha_{1} \mathrm{sal}_{\mathrm{st}}+\alpha_{2} \mathrm{efic}_{\mathrm{it}}+\alpha_{3} \Delta \mathrm{efic}_{\mathrm{it}}+\alpha_{4} \Delta \mathrm{k}_{\mathrm{it}}+\alpha_{5} \Delta \mathrm{k}_{\mathrm{it}-1}+\mathrm{e}_{\mathrm{it}}
$$

A variável emp $\mathrm{st}_{\mathrm{st}} \mathrm{pm}_{\mathrm{it}}$ representa o emprego setorial ponderado pela participação de mercado de cada empresa. ${ }^{9}$ Adaptando-se González e Sala (2014), sal ${ }_{\text {st }}$

9 Como a seção estuda o comportamento das empresas, procurou-se, peremptoriamente, utilizar 
é o salário por setor, efic ${ }_{\mathrm{it}}$ é a proxy de eficiência da empresa e $\Delta$ efic $_{\mathrm{it}}$ é sua taxa de mudança. As duas últimas variáveis independentes dessa equação são $\Delta \mathrm{k}_{\mathrm{it}} \mathrm{e} \Delta \mathrm{k}_{\mathrm{it}-1}$, representando a taxa de acumulação de capital de cada empresa, contemporaneamente e defasada em um período. Conforme González e Sala (2014), o sinal esperado de ambas é positivo. O termo representa os resíduos da estimação. Todas as variáveis estão em log, e os subscritos $i, s$ e $t$ representam, respectivamente, empresa, setor e tempo.

O método utilizado para estimação é o de mínimos quadrados em dois estágios (MQ2E). Por conta da presença de outliers, ${ }^{10}$ o modelo será regredido de forma a ponderar tais observações, tratando problemas de heterocedasticidade (FOX, 2008).

Sobre as dummies setoriais, algumas modificações foram feitas em relação à Tabela 5(ver Anexo A), que retrata os 14 setores e as empresas que pertencem a cada um deles. Cada empresa passa a fazer parte de um setor, sendo o critério de classificação setorial da Bovespa, que considera o setor no qual as atividades da empresa são mais significativas. Com a reclassificação, apenas três setores sofreram modificações: o setor um passou a ter somente a Vale, o setor cinco, somente a Fibria e o setor seis, somente a Klabin. Como as dummies setor-empresa são utilizadas como controles, seus resultados serão removidos da apresentação.

\section{Base de Dados}

O diferencial do imobilizado em milhares de reais deflacionado é a proxy para a variável taxa de investimento $\left(\Delta \mathrm{k}_{\mathrm{it}}\right)$, ou seja, é a diferença do imobilizado no período $t+1$ em relação ao imobilizado no período $t$. Optou-se pelo imobilizado porque captura as expansões das instalações e capacidade produtiva das firmas. Os dados foram obtidos no Economatica (2013), na rubrica imobilizado do balanço patrimonial de cada empresa. O salário real médio de cada setor deflacionado $\left(\mathrm{sal}_{\mathrm{st}}\right)$ e os dados sobre estoque de emprego por setor $\left(\mathrm{emp}_{\mathrm{st}}\right)$ foram obtidos por meio da RAIS (2013).

Além desses dados, foi incluída uma proxy para a eficiência por empresa $\left(\right.$ efic $_{\mathrm{it}}$ ), calculada como a diferença entre o log da receita operacional em milhares de reais e o log do imobilizado em milhares de reais. Tanto a receita operacional quanto o imobilizado estão deflacionados e foram obtidos no Economatica (2013). A definição dessa proxy é baseada no modelo de González e Sala (2014), no qual

variáveis relativas às empresas, que é o caso das seguintes variáveis: $\Delta \mathrm{k}_{\mathrm{it}}, \Delta \mathrm{k}_{\mathrm{it}-1}, \mathrm{efic}_{\mathrm{it}}, \Delta \mathrm{efic}_{\mathrm{it}-1}$, $\operatorname{divluc}_{\mathrm{it}}$ e divluc $\mathrm{it}_{\mathrm{it}-1}$. Não conseguindo-se variáveis relativas ao emprego e salário por empresa,

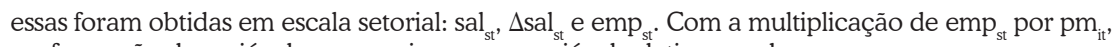
e a formação da variável, conseguiu-se uma variável relativa a cada empresa.

10 A Tabela 7 (ver Anexo A) apresenta as estatísticas de cada variável. Por meio dessa tabela é possível perceber a presença de outliers. 
a produtividade do capital foi calculada subtraindo-se o log do produto interno bruto real pelo log do estoque de capital real. No trabalho desses autores, a produtividade foi calculada de forma agregada para a economia americana; aqui a situação é diferente, pois a ausência de dados sobre produção individual impede o cálculo da produtividade por empresa. Dessa forma, para se obter uma proxy para eficiência produtiva, decidiu-se utilizar a diferença entre a receita operacional e o estoque de capital (imobilizado).

Os dados da RAIS (2013) e do Economatica (2013) tornaram possível a construção da variável participação de mercado de cada empresa $\left(\mathrm{pm}_{\mathrm{it}}\right)$ usando a receita operacional da empresa dividida pela receita operacional do setor. A variável $\mathrm{emp}_{\mathrm{st}} \mathrm{pm}_{\mathrm{it}}$ representa o emprego setorial ponderado pela participação de mercado de cada empresa. Mais uma vez, por conta da impossibilidade de coletar dados de emprego por empresa, a maneira de contornar essa limitação foi utilizar dados do emprego setorial $\left(\mathrm{emp}_{\mathrm{st}}\right.$ ) e multiplicá-lo pela participação de cada empresa no setor ao qual pertence $\left(\mathrm{pm}_{\mathrm{it}}\right)$, utilizando tal variável como proxy para a demanda por emprego de cada firma em seu setor específico.

Sobre as proxies de MSV, divluc $c_{\text {it }}$ foi construída usando-se os dividendos ponderados pelo lucro líquido para cada empresa. Não obstante a proxy divluc it $_{\text {, serão }}$ testadas outras proxies que possam refletir melhor a financeirização das empresas. A recluc ${ }_{i t}$ (receita financeira/lucro líquido) é a proxy de financeirização utilizada para verificar se há alguma relação entre financeirização e a taxa de acumulação do capital, com posterior impacto sobre o emprego. Por fim, a recdesp $p_{i t}$ é a proporção entre receita e despesa financeira para cada empresa. Essa variável também tende a captar a administração financeira das empresas, analisando a relação entre receitas e despesas geradas a partir de diferentes instrumentos financeiros. São dois os canais possíveis de impacto dessa variável: um aumento de recdesp $_{\text {it }}$ pode tanto gerar impactos positivos sobre o investimento(via modelos de crescimento finance-led), quanto também, de forma oposta, gerar redução do investimento, conforme literatura sobre efeitos danosos dos processos de financeirização sobre a acumulação de capital físico. Todos esses dados foram obtidos no Economatica (2013). Por fim, o modelo econométrico, apresentado na próxima seção, será estimado para 52 empresas. Esse é o número máximo de empresas com dados sobre distribuição de dividendos, a variável de interesse, em todo o período selecionado. 


\subsection{Discussão dos Resultados}

A Tabela 3 retrata as estimações do modelo (primeiro estágio) para a taxa de acumulação de capital, $\Delta \mathrm{k}_{\mathrm{it}}$ (equação 7). Cinco formas funcionais foram testadas, o que agrega também um teste da robustez das estimativas. Na primeira forma funcional, o modelo sem o controle das dummies é estimado. Nas outras formas funcionais, são acrescentadas as dummies e as variáveis de financeirização, sequencialmente. As regressões apresentaram problemas de autocorrelação em todas as formas funcionais. Para solucionar esse problema, utilizaram-se erros padrões de Newey-West.

O teste de Hausman, que considera as duas equações do modelo (equações 7 e 8), indicou que a taxa de investimento é uma variável endógena em todas as regressões e, por isso, seria inapropriado tratá-la como exógena, tornando, desse modo, oportuna a especificação e estimação de uma equação para explicá-la.

A validade dos instrumentos ocorre por meio dos testes apresentados por Stock e Yogo (2005). O primeiro teste (MQ2E viés) analisa o viés das estimações do $\mathrm{MQ2E}$ relativo às estimações do MQO. Em todas as formas funcionais rejeitou-se a hipótese nula de que aceitaríamos um viés superior a 5\%. O segundo teste utiliza valores críticos de Stock e Yogo (2005) para determinar se os instrumentos são fracos. Esse teste assinala que o conjunto de instrumentos é fraco se não consegue rejeitar a hipótese nula do teste de Wald (Wald) a 10\%. Da mesma forma como ocorreu com o primeiro teste, todos os testes rejeitaram a hipótese nula. Em ambos os testes, o valor da estatística $F$ deve superar o valor estatístico reportado para denotarmos que o teste rejeita a hipótese nula. 
Tabela 3 - Estimações do primeiro estágio: função de investimento

\begin{tabular}{|c|c|c|c|c|c|}
\hline & (1) & (2) & (3) & (4) & (5) \\
\hline \multirow[t]{2}{*}{$\Delta \mathrm{sal}_{\mathrm{st}}$} & -0.0002 & -0.00004 & -0.004 & 0.0065 & 0.0067 \\
\hline & $(0.015)$ & $(0.015)$ & $(0.015)$ & $(0.014)$ & $(0.013)$ \\
\hline \multirow[t]{2}{*}{ efic $_{i t}$} & 0.0046 & -0.005 & -0.005 & -0.0004 & 0.0002 \\
\hline & $(0.0076)$ & (0.009) & $(0.01)$ & (0.009) & $(0.012)$ \\
\hline \multirow[t]{2}{*}{$\Delta$ efic $_{i t}$} & $-0.832^{* * * *}$ & $-0.830^{* * * *}$ & $-0.835^{\text {k***}}$ & $-0.819^{\text {t*k*}}$ & $-0.822^{* * * *}$ \\
\hline & $(0.051)$ & (0.049) & $(0.047)$ & $(0.057)$ & $(0.065)$ \\
\hline \multirow[t]{2}{*}{$\operatorname{divluc}_{\mathrm{it}}$} & $-0.046^{\text {k**** }}$ & $-0.043^{* * * * *}$ & $-0.037^{* *}$ & $-0.041^{\text {**** }}$ & $-0.033^{* * * *}$ \\
\hline & $(0.011)$ & (0.011) & $(0.012)$ & $(0.011)$ & $(0.011)$ \\
\hline \multirow[t]{2}{*}{$\operatorname{divluc}_{\mathrm{it}-1}$} & $0.027^{*}$ & $0.032^{*}$ & $0.032^{*}$ & $0.029^{*}$ & $0.028 * *$ \\
\hline & $(0.013)$ & $(0.014)$ & $(0.015)$ & (0.014) & $(0.013)$ \\
\hline \multirow[t]{2}{*}{ recluc $_{i t}$} & & & $-0.018^{*}$ & & $-0.015 * *$ \\
\hline & & & $(0.007)$ & & $(0.007)$ \\
\hline \multirow[t]{2}{*}{ recdesp $_{i t}$} & & & & 0.0003 & 0.003 \\
\hline & & & & $(0.0046)$ & $(0.0047)$ \\
\hline \multirow[t]{2}{*}{ constante } & $0.13^{* * *}$ & $0.14^{*}$ & $0.18^{* *}$ & $0.13^{*}$ & $0.19^{* * *}$ \\
\hline & $(0.045)$ & $(0.056)$ & $(0.063)$ & $(0.06)$ & $(0.063)$ \\
\hline $\mathrm{N}$ & 623 & 623 & 606 & 575 & 568 \\
\hline $\mathrm{F}$ & $56.19 * * *$ & $120.92 * * *$ & $117.03^{* * *}$ & $95.44 * * *$ & $90.33^{* * *}$ \\
\hline Hausman & $0.10^{*}$ & $0.00 * * *$ & $0.00 * * *$ & $0.00 * * *$ & $0.00 * * *$ \\
\hline MQ2E vies & 18.37 & 21.34 & 21.36 & 21.76 & 21.38 \\
\hline Wald & 26.87 & 57.53 & 59.92 & 58.54 & 62.30 \\
\hline
\end{tabular}

Fonte: Elaboração própria a partir dos resultados da pesquisa.

Notas: Dummies setoriais foram suprimidas da apresentação nas formas funcionais (2) a (5); entre parênteses estão os erros padrões; ** * é significativa a 1\%, ** a $5 \%$ e * a10\%; F é o teste $F$ da regressão; Hausman é o teste de endogeneidade, com seu p-valor; MQ2E viés e Wald são os testes de validade dos instrumentos, os quais exibem os seus valores críticos.

A variável de interesse, divluc $\mathrm{it}_{\mathrm{it}}$ foi significativa em todas as formas funcionais, apresentando sinal negativo, o que evidencia a robustez do resultado. Este indica que a distribuição de dividendos tem, em média, um efeito negativo de $0,04 \%$ sobre a taxa de acumulação do capital para a amostra de empresas. O setor produtivo é afetado de modo adverso pelo uso da estratégia de MSV quando é conduzida em prol dos acionistas. Esse resultado confirma a relação vista na seção 3 entre a maior distribuição de dividendos e a redução do investimento (ver Gráficos 2 e 3). Entretanto, o resultado advindo da inclusão de outras variáveis no 
modelo não permite afirmar categoricamente que a estratégia de MSV das firmas selecionadas seja financeirizada nos moldes das economias anglo-saxônicas.

Primeiramente, não só o coeficiente de recdesp ${ }_{i t}$ não se apresentou significativo (formas funcionais 4 e 5), mas recluc $c_{i t}$, apesar de significativa e negativa (formas funcionais 3 e 5), não altera significativamente (em termos absolutos) os coeficientes de divluc ${ }_{\mathrm{it}}$. Isso indica que há muito pouco ou nenhuma influência, na amostra selecionada, da administração de receitas e despesas sobre a estratégia de MSV. Em outras palavras, mesmo que seja possível afirmar que a administração de ativos e passivos financeiros afete em média a taxa de acumulação de capital, não se pode afirmar, categoricamente, a partir dos resultados, que a estratégia de MSV se assemelhe estritamente à utilizada nos países anglo-saxões. Por um lado, mesmo que haja distribuição de dividendos significativa, com impactos sobre investimento, por outro lado a financeirização da amostra de empresas brasileiras não mostra indícios de busca por ativos financeiros (especulação) como estratégia para geração de receitas, dado que os dados indicam que as operações financeiras tiveram como objetivo incrementar o financiamento das atividades produtivas.

Esses resultados ajudam também a entender o sinal positivo da variável defasada divluc ${ }_{\mathrm{it}-1}$. No Gráfico 4 , observou-se que a distribuição de dividendos foi crescente ao longo do período analisado. É possível inferir que o crescimento das atividades produtivas e o pagamento de dividendos sejam positivamente correlacionados. Como as firmas demonstraram, em média, uma tendência de crescimento das receitas operacionais, comparativamente ao seu desempenho no setor financeiro (principalmente no tocante ao resultado financeiro), o maior pagamento de dividendos em $t$ - 1 pode ter funcionado como um incentivo para a firma expandir sua capacidade ociosa em $t$ e expandir a produção de modo a compensar as reduções na taxa de acumulação do capital. Isso reforça as conclusões da seção 3, principalmente sobre o destaque do setor produtivo comparativamente ao financeiro na geração de receitas, e fortalece a hipótese de uma financeirização moldada conforme o ambiente institucional do Brasil.

Sobre as demais variáveis explicativas, tanto a taxa de salário médio quanto a eficiência por empresa não foram significativas. Por outro lado, a taxa de eficiência foi significativa em todas as formas funcionais. Seu sinal negativo é esperado: uma vez que as variações de receitas operacionais aumentam (dado o estoque de capital), há maior eficiência operacional-produtiva, o que reduz o incentivo a incrementar o investimento.

Por fim, cabe analisar o impacto das variações na acumulação de capital sobre o emprego. A Tabela 4 apresenta os resultados do segundo estágio (equação 8), tendo como variável dependente o emprego setorial ponderado pela participação de cada empresa no setor. As cinco formas funcionais da Tabela 4 representam, respectivamente, o segundo estágio das cinco formas funcionais da Tabela 3. 
Como ocorreu com o primeiro estágio, todas as regressões apresentaram autocorrelação serial, sendo por isso utilizado o estimador Newey-West.

Tabela 4 - Estimações do segundo estágio: função emprego setorial

\begin{tabular}{|c|c|c|c|c|c|}
\hline & (1) & (2) & (3) & (4) & (5) \\
\hline \multirow[t]{2}{*}{$\mathrm{sal}_{\mathrm{st}}$} & $-0.564^{\text {w**n}}$ & $-0.499^{\text {*** }}$ & $-0.522^{* * *}$ & $-0.544^{* * *}$ & $-0.538^{* *}$ \\
\hline & (0.159) & $(0.179)$ & $(0.187)$ & $(0.170)$ & (0.196) \\
\hline \multirow[t]{2}{*}{$\mathrm{efic}_{\mathrm{it}}$} & $-0.382^{\text {*** }}$ & $-0.410^{\text {kik }}$ & $-0.387^{* * k}$ & $-0.396^{\text {*i. }}$ & $-0.397^{* *}$ \\
\hline & $(0.126)$ & $(0.132)$ & $(0.140)$ & $(0.134)$ & (0.154) \\
\hline \multirow[t]{2}{*}{$\Delta$ efic $_{\text {it }}$} & -0.267 & $7.008^{\text {*k** }}$ & $6.493^{\text {*k***}}$ & $7.165^{\text {t.** }}$ & $7.663^{* * * *}$ \\
\hline & (1.809) & (1.899) & (1.911) & (1.903) & (2.153) \\
\hline \multirow[t]{2}{*}{$\Delta \mathrm{k}_{\mathrm{it}}$} & -0.973 & $7.815^{\text {kikt }}$ & $7.192^{\text {*k* }}$ & $8.113^{\text {wikth }}$ & $8.736^{* * * *}$ \\
\hline & (2.172) & $(2.285)$ & $(2.271)$ & (2.320) & (2.610) \\
\hline \multirow[t]{2}{*}{$\Delta \mathrm{k}_{\mathrm{it}-1}$} & $-0.500^{*}$ & $-0.497^{*}$ & -0.437 & -0.444 & -0.390 \\
\hline & $(0.224)$ & $(0.219)$ & $(0.228)$ & $(0.296)$ & (0.307) \\
\hline \multirow[t]{2}{*}{ constante } & $18.38^{\text {*n***}}$ & $17.40^{\text {*\#*** }}$ & $17.52^{\text {****}}$ & $17.70^{\text {***** }}$ & $17.59^{* * * *}$ \\
\hline & (1.167) & (1.317) & $(1.382)$ & $(1.242)$ & (1.439) \\
\hline $\mathrm{N}$ & 538 & 538 & 515 & 483 & 475 \\
\hline $\mathrm{F}$ & $5.93 * * *$ & $9.06 * * *$ & $7.36 * * *$ & $8.29 * * *$ & $7.42 * * *$ \\
\hline
\end{tabular}

Fonte: Elaboração própria a partir dos resultados da pesquisa.

A taxa de investimento, agora como regressor endógeno, foi significativa a $1 \%$ em todas as formas funcionais, com exceção da primeira, sempre com sinal positivo e apresentando elasticidade maior do que a unidade. Esse resultado denota o impacto positivo da taxa de investimento sobre o emprego, ao mesmo tempo mostrando a importância do MSV sobre o desempenho das empresas: como a divluc $_{\mathrm{it}}$ impacta negativamente a taxa de investimento (primeiro estágio), e essa, por sua vez, atinge positivamente o emprego, a estratégia de MSV termina, em última instância, por reduzir o emprego nos respectivos setores de atividades das empresas.

A respeito das outras variáveis independentes, todas foram, na maior parte dos casos, significativas. O salário real médio e a eficiência (em nível) apresentaram sinais negativos, enquanto a taxa de eficiência teve sinal estimado positivo. $\mathrm{O}$ coeficiente positivo da taxa de eficiência contrasta com os resultados daTabela 3. Nesse caso, a explicação parece repousar no fato de que o aumento da variação da receita operacional, dado a unidade de capital, incrementa as atividades das empresas, incentivandoa contratação de mão de obra.

Em suma, as regressões realizadas nas cinco formas funcionais apresentaram o mesmo padrão, no qual a variável de distribuição de dividendos afetou de modo 
adverso a taxa de investimento, que, por sua vez, impactou positivamente sobre o emprego. A conclusão é de que o comportamento de MSV, apesar de não apresentar traços claros de financeirização à maneira das economias avançadas - em particular, economias anglo-saxônicas-, ainda assim influi, em média, na acumulação de capital da amostra de empresas estudadas e, por conseguinte, produz efeito negativo sobre o emprego nos seus respectivos setores de atividade.

\section{Considerações Finais}

Esse artigo teve o intuito de analisar a financeirização, em especial a estratégia corporativa MSV, sobre a atividade de um conjunto de empresas nãofinanceiras de capital aberto que atuam no Brasil. Esse tema ainda é pouco investigado no Brasil, dada as dificuldades de se analisar tal estratégia em um contexto de relativo baixo desenvolvimento financeiro dos mercados. A esse problema somam-se as dificuldades em trabalhar com bases de dados incompletas sobre variáveis financeiras. Sob tais condições, este estudo investigou empresas nãofinanceiras de capital aberto que operaram no Brasil entre os anos 1997 e 2013. A ideia principal era dar maior suporte à discussão da influência da financeirização sobre as estratégias corporativas, em especial o MSV. Com base em uma avaliação empírica preliminar (seção 3), é possível inferir que as empresas selecionadas aprofundaramo MSV, aumentando a distribuição de dividendos ao longo dos anos. A seção 4 complementa esse estudo, mostrando o impacto deletério da distribuição de dividendos sobre a acumulação de capital.

Entretanto, há indicações que a financeirização dessa amostra de firmas ocorre de forma particular, influenciada pelo ambiente institucional brasileiro. ${ }^{11}$ Primeiramente, as empresas selecionadas possuem, em média, parcela de receitas operacionais significantivamente mais importante que receitas financeiras. Segundo, por todo o período, as empresas operaram com prejuízos financeiros (despesas financeiras maiores que receitas). Ademais, no estudo econométrico realizado, ao se considerar as receitas financeiras conjuntamente à distribuição de dividendos, o coeficiente desta não se modifica significativamente em termos absolutos, o que indica que não há intermediação clara, entre receitas financeiras e taxa de acumulação, da estratégia de MSV. Em outras palavras, a estratégia de distribuição dos dividendos não foi influenciada pela intermediação financeira.

Por fim, ainda que este artigo possa contribuir para o debate sobre a financeirização na economia brasileira, novos estudos devem ser realizados para oferecer maiores detalhes sobre esses resultados e compreender as estratégias financeiras, a administração das receitas e despesas financeiras pelas empresas de capital aberto,

11 Bruno et al. (2011) discutem o ambiente institucional brasileiro e a forma como a financeirização se difundiu circunscrita a esse contexto. 
o grau de vulnerabilidade exposto por essas estratégias e seus impactos sobre a economia no país. Em particular, um melhor entendimento teórico entre o MSV, a dinâmica de acumulação de capital e a geração de emprego se mostra oportuno; esmiuçar os canais pelos quais variáveis financeiras podem afetar variáveis reais.

\section{Referências}

ARANDIA, A. K. O mercado de trabalho frente a crise dos anos 80 e aos planos de estabilização. Indicadores Econômicos FEE, v. 18, n. 4, p. 148-164, 1991.

ARAÚJO, E.; BRUNO, M.; PIMENTEL, D. Financialization against industrialization: a regulationnist approach of the Brazilian Paradox. Revue de la Régulation, n. 11, Apr. 2012.

ARRIGHI, G. The long twentieth century: money, power and the origins of our times. New York: Verso, 1994.

BALTAR, P. E. A. Crescimento da economia e mercado de trabalho no Brasil. In: CARNEIRO, R. M.; MATIJASCIC, M. (ed.).Desafios do desenvolvimento brasileiro. Brasília: IPEA, 2011. p. 149-165.

BELLUZZO, L. G.; ALMEIDA, J. Depois da queda: a economia brasileira da crise da dívida aos impasses do real. Rio de Janeiro: Civilização Brasileira, 2002.

BONIZZI, B. Financialization in developing and emerging countries. International Journal of Political Economy, v. 42, n. 4, p. 83-107, Jan. 2013.

BOYER, R. Is a finance-led growth regime a viable alternative to Fordism? A preliminary analysis. Economy and Society, v. 29, n. 1, p. 111-145, Jan. 2000.

BRUNO, M. et al. Finance-ledgrowth regime no Brasil: estatuto teórico, evidências empíricas e consequências macroeconômicas. Revista de Economia Política, v. 31, n. 5, p. 730-750, 2011.

CHANDLER, A. D. The visible hand: the managerial revolution in American business. Cambridge: Harvard University Press, 1977.

CHESNAIS, F. A teoria do regime de acumulação financeirizado: conteúdo, alcance e interrogações. Economia e Sociedade, v. 11, n. 1, p. 1-44, 2002.

CROTTY, J. The neoliberal paradox: the impact of destructive product market competition and impatient finance on nonfinancial corporations in the neoliberal era. Review of Radical Political Economics, v. 35, n. 3, p. 271-279, 2003.

DETZER, D.; HEIN, E. Financialisation and the financial and economic crises: the case of Germany: IPE working papers. Berlin: Institute for International Political Economy, 2014. Disponível em: https://econpapers.repec.org/RePEc:fes:fstudy:fstudy18. Acesso em 15 mar. 2019.

ECONOMATICA. Balanço patrimonial e demonstrativo de resultados 1997-2013. [s.l: s.n., 2013]. 
ERTURK, I. et al. The democratization of finance? Promises, outcomes and conditions. Review of International Political Economy, v. 14, n. 4, p. 553-575, Aug. 2007.

FILLETI, J. P. Financiamento de empresas não-financeiras de capital aberto no Brasil: proposição de uma abordagem quantílica. 2010. 146 p. Tese (Doutorado em Economia) -Unicamp, Campinas, 2010.

FOX, J. Applied regression analysis and generalized linear models. 2nd. ed. Thousand Oaks: Sage, 2008.

GARAGORRY, J. Economia e política no processo de financeirização do Brasil (1980-2006).Tese (Doutorado em Ciências Sociais) -Pontifícia Universidade Católica, São Paulo, 2007.

GONZÁLEZ, I.; SALA, H. Investment crowding-out and labor market effects of financialization in the US. Scottish Journal of Political Economy, v. 61, n. 5, p. 589-613, Nov. 2014.

GUERRA, L. O mercado de capitais no Brasil: posição relativa, potencial de crescimento e prioridades de ação.2002. Dissertação (Mestrado Profissional em Administração de Empresas) - Fundação Getúlio Vargas, São Paulo, 2002.

HERMANN, J. Auge e declínio do modelo de crescimento com endividamento: o II PND e a crise da dívida externa (1974-1984). In: GIAMBIAGI, F. et al. (ed.). Economia Brasileira Contemporânea (1945-2004). 3. ed. Rio de Janeiro: Elsevier, 2016. p. 93-115.

IBGE. PIA 1997-2013. [s.l: s.n., 2013].

JACONIS, S. Converging and diverging trends in Europe in the presence of Money Manager capitalism: different analytical approaches. In: NATOLI, T.; NUCERA, G.; PELAIA, C. (ed.). Aspetti istituzionali della risposta ai disastri nel sistema delle Nazioni Unite. Napoli: Editoriale Scientifica, 2014. p. 783-792.

JÚNIOR, J. The use of currency derivatives by brazilian companies: an empirical investigation. Revista Brasileira de Finanças, v. 5, n. 2, p. 205-232, 2007.

KARANASSOU, M.; SALA, H. Labourmarket dynamics in Australia: what drives unemployment? Economic Record, v. 86, n. 273, p. 185-209, Sept. 2009.

KRIPPNER, G. R. The financialization of the American economy. Socio-Economic Review, v. 3, n. 2, p. 173-208, 2005.

LAPAVITSAS, C. Financialised Capitalism: Crisis and Financial Expropriation. Historical Materialism, v. 17, n. 2, p. 114-148, jun. 2009.

LAPAVITSAS, C. Theorizing financialization. Work, Employment and Society, v. 25, n. 4, p. 611-626, 2011.

LAZONICK, W. The financialization of the U.S. corporation: what has been lost, and how it can be regained. Seattle University Law Review, v. 36, n. 2, p. 857-909, 2013.

LAZONICK, W.; O'SULLIVAN, M. Maximizing shareholder value: a new ideology for corporate governance. Economy and Society, v. 29, n. 1, p. 13-35, 2000. 
LUCARELLI, B. Financialization and global imbalances: prelude to crisis. Review of Radical Political Economics, v. 44, n. 4, p. 429-447, 2012.

MADEIRA, R. Restrições financeiras nas empresas brasileiras de capital aberto: a relevância da estrutura de capital para o investimento. Revista do BNDES, v. 39, p. 69-122, 2013.

MIRANDA, B. Impactos da financeirização sobre a fragilidade micro e macroeconômica: um estudo para a economia brasileira entre os anos de 1995-2012. 2013. Tese (Doutorado em Economia) -Universidade Federal de Minas Gerais, Belo Horizonte,2013.

MIRANDA, B.; CROCCO, M.; SANTOS, F. Financeirização e governança corporativa: um estudo sobre a estrutura de controle das empresas não-financeiras do novo mercado da BMËFbovespa. Brazilian Keynesian Review, v. 3, n. 1, p. 75-94, 2017.

MISHKIN, F. S. Why we shouldn't turn our backs on financial globalization. IMF Staff Papers, v. 56, n. 1, p. 139-170, 2009.

MYRDAL, G. Contra a corrente. Rio de Janeiro: Campus, 1977.

ORHANGAZI, O. Financialization and capital accumulation in the non-financial corporate sector: a theoretical and empirical investigation of the US economy: 1973-2003. Political Economy Research Institute, 2007. (Working paper, n. 149)

OSTRY, D.; LOUNGANI, P.; FURCERI, D. Neoliberalism: Oversold? Finance 8 Development, v. 53, n. 2, p. 38-41, 2016.

PALLEY, T. I. Financialization: what it is and why it matters.In: PALLEY, T. I. (ed.). Financialization. London: Palgrave Macmillan UK, 2013. p. 17-40.

PAULANI, L. Acumulação sistêmica, poupança externa e rentismo: observações sobre o caso brasileiro. Estudos Avançados, v. 27, n. 77, p. 237-264, 2013.

PINTO, E.; GONÇALVES, R. Modelos de desenvolvimento e desempenho macroeconômico: Brasil.Rio de Janeiro: IE-UFRJ, 2015. (Texto para discussão, 017). Disponível em: http:// www.ie.ufrj.br/images/pesquisa/publicacoes/discussao/2015/TD_IE_017_2015_PINTO_ GONALVES.pdf. Acesso em: 14 abr. 2019.

PLIHON, D. As grandes empresas fragilizadas pela finança. In: CHESNAIS, F. (ed.).A finança mundializada. São Paulo: Boitempo, 2005. p. 256.

RAIS. Estoque de emprego por setor 1997-2013. [s.l: s.n., 2013].

RAMOS, L.; BRITTO, M. O funcionamento do mercado de trabalho metropolitano brasileiro no período 1991-2002: tendências, fatos estilizados e mudanças estruturais. Rio de Janeiro: IPEA, 2004. (Texto para Discussão, n.11).

SANT'ANNA, A. Mercado de capitais: evolução recente e financiamento das empresas brasileiras no período 2004-2007. In: FERREIRA, F.; MEIRELLES, B. (org.). Ensaios sobre economia financeira. Rio de Janeiro: Banco Nacional de Desenvolvimento Econômico e Social, 2009. p. 318. v.1. 
STOCK, J. H.; YOGO, M. Testing for weak instruments in linear IV regression. In: ANDREWS, D.; STOCK, J. H. (org.). Identification and inference for econometric models: essays in honor of Thomas Rothenberg. New York: Cambridge University Press, 2005. p. 80-108.

STOCKHAMMER, E. Financialisation and the slowdown of accumulation. Cambridge Journal of Economics, v. 28, n. 5, p. 719-741, 2004.

TRIDICO, P.; PARIBONI, R. Inequality, financialization, and economic decline. Journal of Post Keynesian Economics, v. 41, n. 2, p. 236-259, Apr. 2018.

VAN DER ZWAN, N. Making sense of financialization. Socio-Economic Review, v. 12, n. 1, p. 99-129, Jan. 2014.

VIEIRA, E. R. Mercado de capitais e governança corporativa no Brasil: reflexões sobre os movimentos recentes.In: ENCONTRO REGIONAL DE ECONOMIA, 7.,2002. Anais [...] Fortaleza: ANPEC, 2002.

ZONENSCHAIN, C. Estrutura de capital das empresas no Brasil. Revista do BNDES, v. 10, p. 63-92, 1998.

ZYSMAN, J. Governments, markets and growth: financial systems and the politics of industrial change.Ithaca: Cornell University, 1983. 
Tabela 5 - Empresas e setores

\begin{tabular}{|c|c|}
\hline Setores & Empresas \\
\hline Extrativa mineral & $\begin{array}{l}\text { Ferbasa, Petrobras S.A., Companhia Siderúrgica Nacional e Vale } \\
\text { S.A. }\end{array}$ \\
\hline $\begin{array}{l}\text { Indústria metalúr- } \\
\text { gica }\end{array}$ & $\begin{array}{l}\text { Electro Aço Altona S.A., Ferbasa, Mangels Industrial S.A., Paran- } \\
\text { apanema S.A., Companhia Siderúrgica Nacional, Tekno S. A. e } \\
\text { Usiminas S. A. }\end{array}$ \\
\hline Indústria mecânica & $\begin{array}{l}\text { Bardella S.A., Estrela S.A., Eternit S.A., Eucatex S.A., Forja Taurus } \\
\text { S.A, IGB S.A., Inepar S.A., Kepler S.A., MetalGráfica Iguaçu S.A., } \\
\text { Metisa S.A., Mundial S.A., Nadir S.A., Recrusul S.A., Springer } \\
\text { S.A., Tec Toy S.A. e Whirlpool S.A. }\end{array}$ \\
\hline $\begin{array}{l}\text { Material e trans- } \\
\text { porte }\end{array}$ & $\begin{array}{l}\text { DHB S.A., Embraer S.A., Fras-Le S.A., Iochpe S.A., Marcopolo } \\
\text { S.A., Plascar S.A., Randon S.A., Recrusul S.A., Riosulense S.A., } \\
\text { Tupy S.A., WEG S.A. e WLM S.A. }\end{array}$ \\
\hline $\begin{array}{l}\text { Madeira e mobil- } \\
\text { iário }\end{array}$ & Fibria S.A. e Klabin S.A. \\
\hline Papel e gráfica & Fibria S.A. e Klabin S.A. \\
\hline $\begin{array}{l}\text { Borracha, fumo e } \\
\text { couro }\end{array}$ & Souza Cruz S.A. \\
\hline Indústria química & $\begin{array}{l}\text { Dimed S.A., Elekeiroz S.A., Petrobras S.A., Companhia Siderúr- } \\
\text { gica Nacional e Refinaria de Petróleo Manguinhos S.A. }\end{array}$ \\
\hline Indústria têxtil & $\begin{array}{l}\text { Buettner S.A., Cedro, Companhia Hering, Dohler S.A., Guara- } \\
\text { rapes S.A., Karsten S.A. e Teka S.A. }\end{array}$ \\
\hline $\begin{array}{l}\text { Indústria de calça- } \\
\text { dos }\end{array}$ & Alpargatas S.A. \\
\hline $\begin{array}{l}\text { Alimentos e bebi- } \\
\text { das }\end{array}$ & Ambev S.A., BRF S.A., Minupar S.A. e Oderich S.A \\
\hline $\begin{array}{l}\text { Serviços de utili- } \\
\text { dade pública }\end{array}$ & $\begin{array}{l}\text { Ampla Energia e Serviços S.A., Casan, CEEE-GT, CEG, Celpa, } \\
\text { Celpe, Cesp, Coelba, Coelce, Comgas, Cosern, Energisa-MT, Light } \\
\text { S.A. e Sabesp . }\end{array}$ \\
\hline Construção civil & $\begin{array}{l}\text { Construtora Adolpho S.A., Cyrela Realty, João Fortes S.A., } \\
\text { Mendes Júnior Engenharia S.A., Rossi Residencial S.A. e Sultepa } \\
\text { S.A. }\end{array}$ \\
\hline Comércio & $\begin{array}{l}\text { Lojas Americanas S.A., Parque Hopi Hari S.A., Raia Drogasil S.A., } \\
\text { Saraiva S.A. e Via Varejo S.A. }\end{array}$ \\
\hline
\end{tabular}

Fonte: Elaboração própria a partir de dados da Bovespa, Economatica e RAIS 
Tabela 6 - Definição das variáveis

\begin{tabular}{|c|c|c|c|c|c|c|c|c|c|}
\hline \multicolumn{3}{|l|}{ Variáveis } & \multicolumn{7}{|c|}{ Definição } \\
\hline \multicolumn{3}{|c|}{ Receita operacional } & \multicolumn{7}{|c|}{$\begin{array}{l}\text { Receita com a venda de produtos e mercadorias e a pre- } \\
\text { stação de serviços. }\end{array}$} \\
\hline \multicolumn{3}{|c|}{ Receita financeira } & \multicolumn{7}{|c|}{$\begin{array}{l}\text { Receita com juros recebidos, descontos obtidos e com } \\
\text { rendimentos nominais de aplicações financeiras. }\end{array}$} \\
\hline \multicolumn{3}{|c|}{$\begin{array}{l}\text { Receitas de aplicações } \\
\text { financeiras }\end{array}$} & \multicolumn{7}{|c|}{ Receita de rendimentos nominais de ativos financeiros. } \\
\hline \multicolumn{3}{|c|}{$\begin{array}{l}\text { Variações cambiais e/ou } \\
\text { monetárias }\end{array}$} & \multicolumn{7}{|c|}{$\begin{array}{l}\text { Receita ou despesa advinda da oscilação do câmbio e/ou } \\
\text { moeda sobre ativos e operações financeiras. }\end{array}$} \\
\hline \multicolumn{3}{|c|}{$\begin{array}{l}\text { Encargos de operações } \\
\text { financeiras }\end{array}$} & \multicolumn{7}{|c|}{$\begin{array}{l}\text { Despesa financeira com exceção da despesa com a vari- } \\
\text { ação cambial e/ou monetária. }\end{array}$} \\
\hline \multicolumn{3}{|c|}{ Lucro não financeiro } & \multicolumn{7}{|c|}{$\begin{array}{l}\text { Diferença da receita operacional com a despesa opera- } \\
\text { cional. }\end{array}$} \\
\hline \multicolumn{3}{|c|}{ Lucro (prejuízo) financeiro } & \multicolumn{7}{|c|}{ Diferença da receita financeira com a despesa financeira. } \\
\hline \multicolumn{3}{|l|}{ Lucro líquido } & \multicolumn{7}{|c|}{$\begin{array}{l}\text { Soma do lucro nãofinanceiro com o lucro financeiro depois } \\
\text { dos impostos. }\end{array}$} \\
\hline \multicolumn{3}{|c|}{ Dívida bruta (total) } & \multicolumn{7}{|c|}{$\begin{array}{l}\text { Total de empréstimos e financiamentos de curto e longo } \\
\text { prazo. }\end{array}$} \\
\hline \multicolumn{3}{|l|}{ Imobilizado } & \multicolumn{7}{|c|}{$\begin{array}{l}\text { Bens necessários à manutenção das atividades da empresa, } \\
\text { caracterizados por se apresentarem na forma tangível. }\end{array}$} \\
\hline \multicolumn{3}{|l|}{ Lucro retido } & \multicolumn{7}{|c|}{$\begin{array}{l}\text { Lucro apropriado pela empresa para atender a outras finali- } \\
\text { dades, como o autofinanciamento. }\end{array}$} \\
\hline \multicolumn{3}{|l|}{ Dividendos } & \multicolumn{7}{|c|}{$\begin{array}{l}\text { Parte do lucro da empresa que é distribuído para os acioni- } \\
\text { stas. }\end{array}$} \\
\hline \multicolumn{10}{|c|}{$\begin{array}{l}\text { Fonte: Elaboração própria a partir de dados de Economatica, Portal de Contabilidade, Re- } \\
\text { ceita Federal }\end{array}$} \\
\hline \multicolumn{10}{|c|}{ Tabela 7 - Estatísticas das variáveis } \\
\hline$\Delta \mathrm{k}_{\mathrm{it}}$ & $\mathrm{sal}_{\mathrm{st}}$ & $\mathrm{sal}_{\mathrm{st}}$ & efic $_{\text {it }}$ & efic $_{\text {it }}$ & $\mathrm{emp}_{\mathrm{st}} \mathrm{pm}_{\mathrm{it}}$ & $\mathrm{pm}_{\mathrm{it}}$ & divluc $_{\text {it }}$ & recluc $_{\mathrm{it}}$ & recdesp $_{\text {it }}$ \\
\hline 832 & 884 & 832 & 860 & 808 & 884 & 884 & 884 & 884 & 884 \\
\hline 868.799 & 1775 & 101 & 1,06 & 0,03 & 55.803 & 8,18 & 0,59 & 1,84 & 0,70 \\
\hline 6.688 .794 & 1204 & 113 & 1,12 & 0.36 & $2.18 \mathrm{e}+05$ & 26,05 & 3,34 & 27,01 & 1,95 \\
\hline$-2.13 e+07$ & 147 & -407 & $-1,45$ & $-2,19$ & 50,23 & 0,02 & $-34,97$ & $-116,26$ & $-3,14$ \\
\hline $9.99 e+07$ & 6008 & 344 & 5,79 & 4,63 & $2.76 e+06$ & 327,00 & 81,38 & 765,79 & 33,74 \\
\hline
\end{tabular}

Fonte: Elaboração própria a partir das estatísticas do stata.

Nota: Dp é o desvio padrão.

Recebido em: 09/06/2017.

Aceito em: 22/03/2018. 